\title{
Targeted therapies for diarrhea-predominant irritable bowel syndrome
}

This article was published in the following Dove Press journal:

Clinical and Experimental Gastroenterology

24 May 2012

Number of times this article has been viewed

\section{Kevin W Olden}

Department of Medicine, St Joseph's Hospital and Medical Center, Phoenix, AZ, USA
Correspondence: Kevin W Olden St Joseph's Hospital and Medical Center, 350 West Thomas Road, Phoenix, AZ 85012, USA

Tel + I 6024068778

$\mathrm{Fax}+\mathrm{I} 6024067186$

Email kevin.olden@CHW.edu
Abstract: Irritable bowel syndrome (IBS) causes gastrointestinal symptoms such as abdominal pain, bloating, and bowel pattern abnormalities, which compromise patients' daily functioning. Common therapies address one or two IBS symptoms, while others offer wider symptom control, presumably by targeting pathophysiologic mechanisms of IBS. The aim of this targeted literature review was to capture clinical trial reports of agents receiving the highest recommendation (Grade 1) for treatment of IBS from the 2009 American College of Gastroenterology IBS Task Force, with an emphasis on diarrhea-predominant IBS. Literature searches in PubMed captured articles detailing randomized placebo-controlled trials in IBS/diarrhea-predominant IBS for agents receiving Grade I (strong) 2009 American College of Gastroenterology IBS Task Force recommendations: tricyclic antidepressants, nonabsorbable antibiotics, and the $5-\mathrm{HT}_{3}$ receptor antagonist alosetron. Studies specific for constipation-predominant IBS were excluded. Tricyclic antidepressants appear to improve global IBS symptoms but have variable effects on abdominal pain and uncertain tolerability; effects on stool consistency, frequency, and urgency were not adequately assessed. Nonabsorbable antibiotics show positive effects on global symptoms, abdominal pain, bloating, and stool consistency but may be most efficacious in patients with altered intestinal microbiota. Alosetron improves global symptoms and abdominal pain and normalizes bowel irregularities, including stool frequency, consistency, and fecal urgency. Both the nonabsorbable antibiotic rifaximin and the 5- $\mathrm{HT}_{3}$ receptor antagonist alosetron improve quality of life. Targeted therapies provide more complete relief of IBS symptoms than conventional agents. Familiarization with the quantity and quality of evidence of effectiveness can facilitate more individualized treatment plans for patients with this heterogeneous disorder.

Keywords: antidepressant therapy, antibiotic therapy, alosetron, evidence, targeted review

\section{Introduction}

Irritable bowel syndrome (IBS) is a chronic functional gastrointestinal (GI) disorder characterized by episodes of abdominal pain and/or discomfort and altered bowel habits. A previous systematic review of the literature showed that the prevalence of IBS ranged from $3 \%$ to $20 \%$ in North America, with most estimates falling between $10 \%$ and $15 \% .{ }^{1} \mathrm{~A}$ more recent community-based survey supports these earlier estimates, finding a prevalence of IBS in the US of approximately $14.1 \% .^{2}$ More than $80 \%$ of the surveyed patients were 18-54 years of age, and 64\% were women. Further, among US patients with symptoms of IBS, more than three-quarters had not received a definitive diagnosis. ${ }^{2}$ IBS diagnoses are now often classified according to three symptom patterns: diarrhea-predominant IBS (IBS-D), constipation-predominant IBS (IBS-C), and an 
alternating pattern of these two (IBS-A). The true prevalence of each IBS subtype is not established, but IBS-A and IBS-D are thought to be more common..$^{2-4}$

The negative impact of IBS symptoms on daily functioning and quality of life can be substantial. The IBS in the Real World Survey, ${ }^{5}$ conducted by the International Foundation of Functional Gastrointestinal Disorders, found that nearly half of patients diagnosed with IBS experience daily symptoms. Among survey respondents, $26 \%$ reported missing at least 1 day of work or school during the preceding 3 months (average 7.9 days), and 68\% reported missing at least 1 day of personal activities (average 10.5 days) because of their illness. ${ }^{5}$ Nearly $90 \%$ of patients with IBS-D report experiencing abdominal pain, gas, and sudden urgency ${ }^{5}$ and, as symptom severity increases, so too does the level of impairment in daily functioning and quality of life. Patients with severe IBS symptoms may experience quality of life impairments that are comparable with, or even greater than, those associated with diabetes or depression. ${ }^{6,7}$

In 2009, the American College of Gastroenterology (ACG) IBS Task Force updated its evidence-based position statement on the management of IBS. ${ }^{3}$ In the update, the Task Force determined that the strongest evidence for efficacy in IBS-D existed for three classes of medications: tricyclic antidepressants (TCAs), antibiotics (ie, rifaximin), and the $5-\mathrm{HT}_{3}$ antagonist alosetron. ${ }^{3}$ Each class received a strong recommendation for clinical use in IBS (Grade 1B), indicating that the evidence is of moderate to high quality and that the benefits clearly outweigh any risk or burden of therapy. ${ }^{3}$ To provide further detail regarding the ACG recommendations, a comprehensive search of the literature was carried out for published clinical studies involving these agents in the treatment of IBS, with special attention to the IBS-D subtype, with a goal of highlighting the underlying pathophysiologic mechanisms and delineating the breadth of their respective treatment effects.

\section{Methods}

A literature search using PubMed was conducted for randomized placebo-controlled trials in IBS reported in English over the past 25 years and used the search terms "irritable bowel syndrome," "colonic diseases," "functional disease," "IBS," "spastic colon," and/or "irritable colon." Trials evaluating IBSC, those conducted in children, clinical case studies, open-label studies, and studies with an active comparator alone (ie, studies with no placebo arm) were excluded. Articles that evaluated TCAs, antibiotics, or alosetron in IBS were included for this review. To capture any other relevant clinical trials meeting our inclusion criteria that had not been published in full, similar searches were carried out to find congress abstracts in EMBASE, Biosis, Inside Conferences on Dialog, and Conference Papers Index from the past 5 years; relevant information from these searches was included.

\section{Results \\ Pathophysiology}

The pathophysiology of IBS is traditionally linked to a complex interaction between altered gut motility, visceral hypersensitivity, and environmental stress. Although IBS-D is generally thought to be associated with increased motility patterns and IBS-C with decreased motility, no consensus definition exists on the pattern of motility responsible for either bowel pattern abnormality. ${ }^{8}$ The key role of serotonin in intestinal motor and secretory function has given rise to the hypothesis that altered serotonin signaling leads to either constipation or diarrhea in IBS. ${ }^{9,10}$ Specifically, increased serotonin activity may be associated with IBS-D, and decreased serotonin activity may be associated with IBS-C. ${ }^{11,12}$ In addition to these well-recognized abnormalities, a dysfunctional brain-gut axis involving the central, autonomic, and enteric nervous systems has also been implicated in IBS pathophysiology. Other theories proposed in IBS include various causes such as inflammation, disturbances in immune function, and alterations in the gut microbiota. ${ }^{13-15}$

\section{Conventional therapies}

The management of IBS often includes the use of conventional therapies, which are those that are directed toward specific symptoms of IBS (eg, loperamide for diarrhea, laxatives for constipation, antispasmodics for abdominal pain). ${ }^{15,16}$ Because of the heterogeneous nature of their symptoms, patients with IBS are often treated with medications from more than one drug class in an effort to achieve relief. However, use of multiple conventional therapies has not provided sufficient benefit, and IBS patients have expressed dissatisfaction with these treatment regimens. In the IBS in the Real World Survey, $50 \%$ of respondents rated their over-the-counter drug as "not effective" in relieving IBS symptoms. Few controlled trials have demonstrated efficacy for these conventional agents in IBS, despite their frequent use. Furthermore, greater drug exposure from use of multiple therapies may lead to higher safety risks.

\section{Targeted therapies}

In contrast with conventional therapies, which treat only one specific symptom of IBS, targeted treatment strategies are directed at addressing the underlying pathophysiologic 
mechanisms that are believed to cause IBS. These targeted treatments have the potential to relieve multiple rather than single symptoms of IBS. For example, the TCA imipramine has been shown to prolong both orocecal and whole gut transit times in patients with IBS-D, ${ }^{17}$ which is likely the result of its cholinergic and histaminergic antagonism. Additionally, inhibition of the reuptake of norepinephrine and/or serotonin (depending on the TCA) both centrally and peripherally can reduce nociception. ${ }^{9,10,18,19}$ In view of the controversial hypothesis that small intestinal bacterial overgrowth (SIBO) may play a role in the pathogenesis of IBS, ${ }^{20}$ nonabsorbable antibiotics have been investigated for the treatment of IBS, ${ }^{21,22}$ where benefits are presumably due to effects on gut microflora. Alosetron, a selective 5- $\mathrm{HT}_{3}$ antagonist, has also been shown to provide multisymptom relief in IBS. 5- $\mathrm{HT}_{3}$ receptors are extensively distributed on enteric neurons in the human GI tract. Antagonism by alosetron at $5-\mathrm{HT}_{3}$ receptors leads to reduction in visceral pain, ${ }^{23}$ slowed colonic transit, ${ }^{24}$ and decreased GI secretions, ${ }^{25}$ actions that address the underlying pathophysiological mechanisms that are operant in IBS. Of these agents, alosetron is currently the only Food and Drug Administration (FDA)-approved agent for the treatment of women with severe IBS-D. ${ }^{26}$ In this article we review the current evidence for each of these agents as it pertains to IBS-D.

\section{Antidepressants}

In its updated position statement, the ACG IBS Task Force asserted that TCAs are more effective than placebo at relieving global IBS symptoms, noting that these agents also appear to reduce abdominal pain. ${ }^{3}$ A recent meta-analysis including 579 IBS patients treated with TCAs across nine studies showed short-term ( $\leq 12$ weeks) benefits. ${ }^{27}$ In this review, symptoms of IBS were less likely to persist with TCA therapy than with placebo (relative risk $0.68 ; 95 \%$ confidence interval [CI] 0.56-0.83); the number needed to treat to prevent IBS symptoms from persisting in one patient was four (95\% CI 3-8). ${ }^{27}$ Unfortunately, no long-term studies have evaluated the use of TCAs in the treatment of IBS, and therefore the efficacy (and safety) of extended treatment with TCAs remains uncertain. ${ }^{3}$

TCAs may be effective in IBS, particularly in IBS-D, by both central and peripheral mechanisms that include increasing pain thresholds, altering visceral sensation, relieving concomitant depression, and altering gut transit times., ${ }^{3,27}$ The anticholinergic effects of the TCAs and their ability to prolong intestinal transit times are the reasons these agents are preferred over the selective serotonin-reuptake inhibitors (SSRIs) in IBS-D., ${ }^{3,17,27}$
Although TCAs were first used in the treatment of functional bowel disorders more than 30 years ago, ${ }^{16}$ only a limited number of controlled trials have evaluated their efficacy in IBS, and even fewer have been carried out in patients with IBS-D (Table 1). ${ }^{28-33}$ Amitriptyline, ${ }^{28,29}$ desipramine, ${ }^{30,31}$ and imipramine ${ }^{32,33}$ have each been evaluated in two randomized controlled trials in patients with IBS. Four of these trials were small, including 51 or fewer patients, ${ }^{28-30,33}$ one included 107 patients, ${ }^{32}$ and the largest TCA trial to date included 431 patients, who were divided into two treatment groups: pharmacotherapy and psychoeducation. ${ }^{31}$ In five of the six trials, IBS was diagnosed using Rome $\mathrm{I}^{28,31}$ or Rome II ${ }^{29,32,33}$ diagnostic criteria, while in one, the diagnosis was made by a comprehensive history and physical exam with laboratory and imaging studies ruling out organic disease..$^{30}$ Only one trial limited enrollment specifically to IBS-D patients, ${ }^{29}$ and of the two trials that characterized randomized patients by predominant bowel disturbance (ie, diarrhea or constipation), ${ }^{30,33}$ only one reported treatment results by IBS subtype. ${ }^{30}$

\section{Amitriptyline}

Rajagopalan et $\mathrm{al}^{28}$ evaluated the effects of amitriptyline (25$75 \mathrm{mg}$ at bedtime) compared with placebo over 12 weeks in 40 adults with IBS. Amitriptyline was significantly superior to placebo in terms of the percentage of patients showing global improvement (63.6\% vs $25.9 \%$; $P<0.01$ ), number of days per week with abdominal pain ( 1.45 days vs 4.00 days; $P<0.01)$, number of days per week that patients felt well (5.18 days vs 1.91 days; $P<0.001)$, and number of days per week with satisfactory bowel movements (5.27 days vs 3.09 days; $P<0.05)$. In a study limited to IBS-D patients $(\mathrm{N}=50)$, Vahedi et $\mathrm{al}^{29}$ reported that amitriptyline $10 \mathrm{mg}$ given every night for 2 months produced significant improvement in IBS symptoms $(P=0.005)$, reduction in the frequency of patients with loose stools each day $(12 \%$ vs $28 \% ; P<0.05)$, and a higher percentage of patients with a complete response $(63 \%$ vs $26 \% ; P=0.01$ ) compared with placebo. Abdominal pain relief did not differ between the two treatment groups.

\section{Imipramine}

In an evaluation of 51 patients with IBS, 73\% of whom had IBS-D, Talley et $\mathrm{al}^{33}$ compared the effects of imipramine $(25-50 \mathrm{mg} / \mathrm{d})$ and citalopram $(20-40 \mathrm{mg} / \mathrm{d})$ with those of placebo over 12 weeks of treatment. Neither active treatment was superior to placebo on the primary outcome of adequate relief of IBS symptoms. Likewise, abdominal pain scores did not significantly differ between the active treatment and placebo groups. However, imipramine was associated 


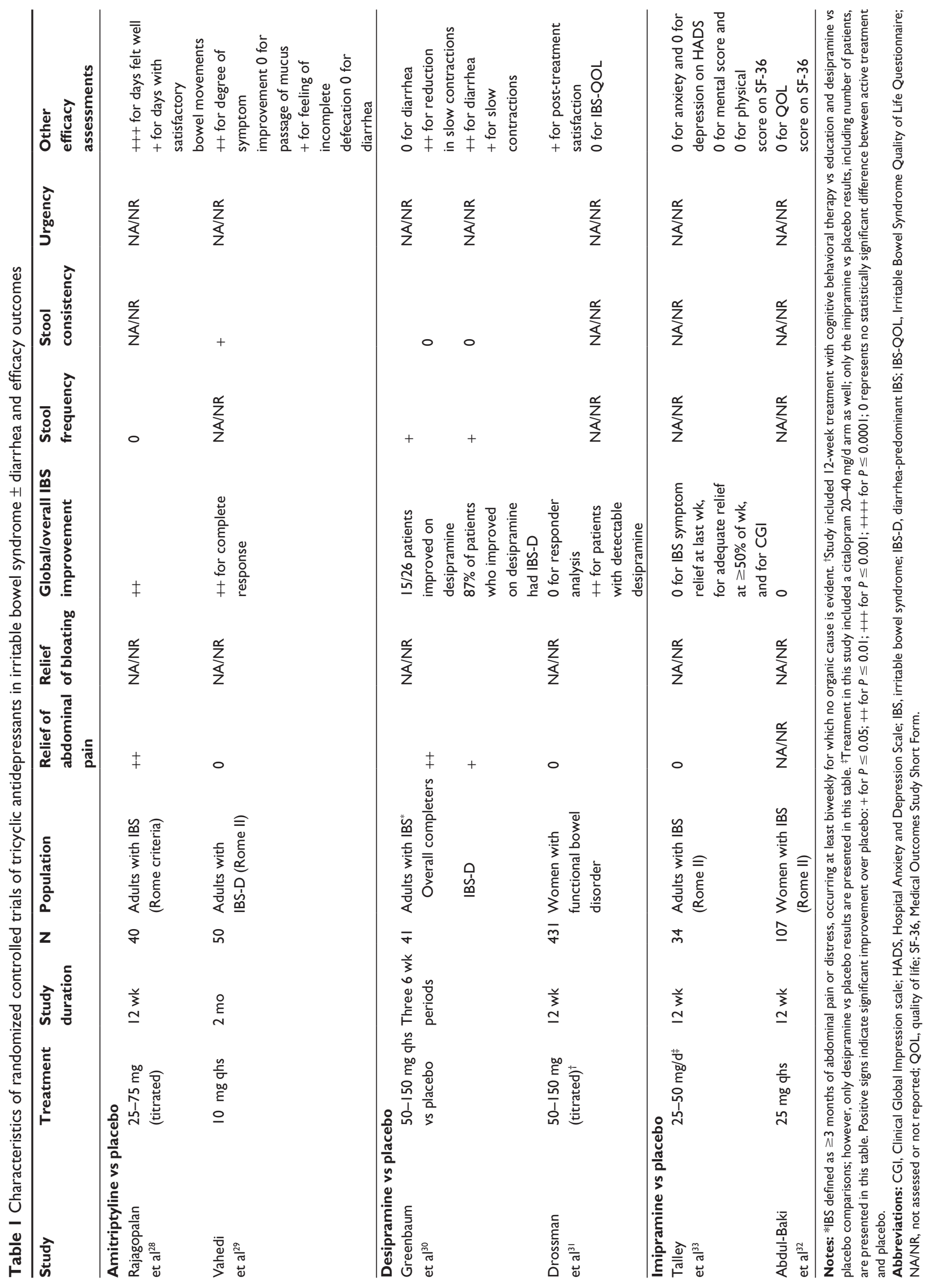


with significant reductions in the Bowel Symptom Severity Rating Scale scores for both disability $(P=0.03)$ and distress $(P=0.05)$ compared with placebo. More patients receiving imipramine than citalopram or placebo reported side effects, but these differences were not significant. ${ }^{33}$ In a second study, reported by Abdul-Baki et al, ${ }^{32} 107$ female patients with IBS who had failed antispasmodics were randomized to receive imipramine (25-50 $\mathrm{mg}$ at bedtime) or placebo. Patient-reported global symptom relief, the primary outcome measure, did not differ significantly between those patients treated with imipramine and those treated with placebo $(42.4 \%$ vs $25.0 \% ; P=0.06){ }^{32}$

\section{Desipramine}

In a double-blind crossover study comparing desipramine, atropine, and placebo, Greenbaum et $\mathrm{al}^{30}$ examined 28 patients with IBS (nine constipation-predominant and 19 diarrhea-predominant by self-report) and found that the mean pain index score decreased during all test periods, with desipramine providing statistically significant pain reduction compared with both atropine $(P<0.025)$ and placebo $(P<0.0025)$. The improvement found in patients with diarrhea predominance accounted for these differences $(P<0.01)$. Of the 15 desipramine-treated patients reporting global improvement while taking desipramine, $87 \%(\mathrm{n}=13)$ had diarrhea predominance. ${ }^{30}$

In the largest trial evaluating a TCA, Drossman et $\mathrm{al}^{31}$ compared desipramine and placebo in a subset of 431 patients with functional bowel disorders, more than $80 \%$ of whom had IBS. Patients were randomized to receive pharmacotherapy $(\mathrm{n}=216)$ with either desipramine $(50-150 \mathrm{mg} / \mathrm{d})$ or placebo for 12 weeks or psychoeducation $(n=215)$ with either twelve 1-hour sessions of cognitive behavioral therapy or twelve educational sessions for review of symptom diaries and educational material on functional bowel disorders. Using a composite endpoint consisting of four ratings (treatment satisfaction, global well-being, pain on the McGill Pain Questionnaire, and quality of life on the IBS Quality of Life Questionnaire) as the primary outcome measure, investigators found no significant difference between desipramine and placebo in the intent-to-treat population; however, desipramine was statistically superior to placebo in the per-protocol assessment, consisting of all patients who completed at least eight visits during the study (desipramine $\mathrm{n}=97$, placebo $\mathrm{n}=56 ; P=0.03) .{ }^{31}$

\section{Adverse events in IBS patients treated with TCAs}

Adverse events of dizziness, drowsiness, constipation, and dry mouth occurred with greater frequency during
TCA treatment compared with placebo. ${ }^{30-33}$ In the trial by Drossman et al, ${ }^{31}$ adverse effects were cited as the primary reason for dropout $(\mathrm{n}=26,19.3 \%)$ in the desipramine group compared with those receiving placebo $(n=3$, $5.5 \%$ ). Although anticholinergic effects often develop with increasing TCA dosages, ${ }^{16}$ the secondary amines (eg, desipramine, nortriptyline) are generally better tolerated than the tertiary amines (eg, amitriptyline, imipramine) because of their lower affinity for cholinergic, histaminergic, and $\alpha$-adrenergic receptors. ${ }^{16}$ Other safety concerns with TCAs include the risk of cardiac arrhythmias and the potential for fatal overdose, which is of particular concern in IBS patients because of a higher prevalence of suicidal ideation in this population. ${ }^{16,34}$

\section{Selective serotonin-reuptake inhibitors}

Five small randomized placebo-controlled studies assessed the capacity of SSRIs to improve IBS symptoms..$^{33,35-38}$ Relevant studies are summarized in Table 2. Only one study ${ }^{38}$ reported a significant improvement in the number of days per week with abdominal pain in patients taking citalopram compared with those taking placebo, and one ${ }^{36}$ reported that paroxetine produced a significant improvement in overall well-being compared with placebo. Limited information is available regarding tolerability, with dropout rates related as similar in two studies ${ }^{33,38}$ and overall adverse events described as comparable in three studies; $; 3,35,37$ one study reported no adverse event data. ${ }^{36}$ However, given the propensity of SSRIs to commonly cause GI adverse events of nausea, vomiting, and diarrhea, TCAs may have more utility in IBS-D than SSRIs appear to have.

\section{Nonabsorbable antibiotics}

With the growing body of evidence implicating a potential role of intestinal bacteria in IBS pathophysiology, ${ }^{39-42}$ the use of antibiotics to normalize gut flora has been investigated as a treatment for IBS. Several reports suggest a link between IBS and SIBO $;^{20,21,43,44}$ however, the association remains controversial. ${ }^{45,46}$ The presence of SIBO may be associated with the IBS symptoms of gas, bloating, and altered bowel function through the fermentation of ingested lactulose or other carbohydrates by gut bacteria and stimulation of a gut immune response. ${ }^{20,21}$ Lactulose hydrogen breath test (LHBT) results have varied widely, with the presence of SIBO being diagnosed in $10 \%{ }^{47}$ to $84 \%{ }^{21}$ of IBS patients. A recent systematic review and meta-analysis of studies examining SIBO in IBS noted a pooled prevalence of 54\% (95\% CI 32\%-76\%) with a positive LHBT result. ${ }^{40}$ The use of 


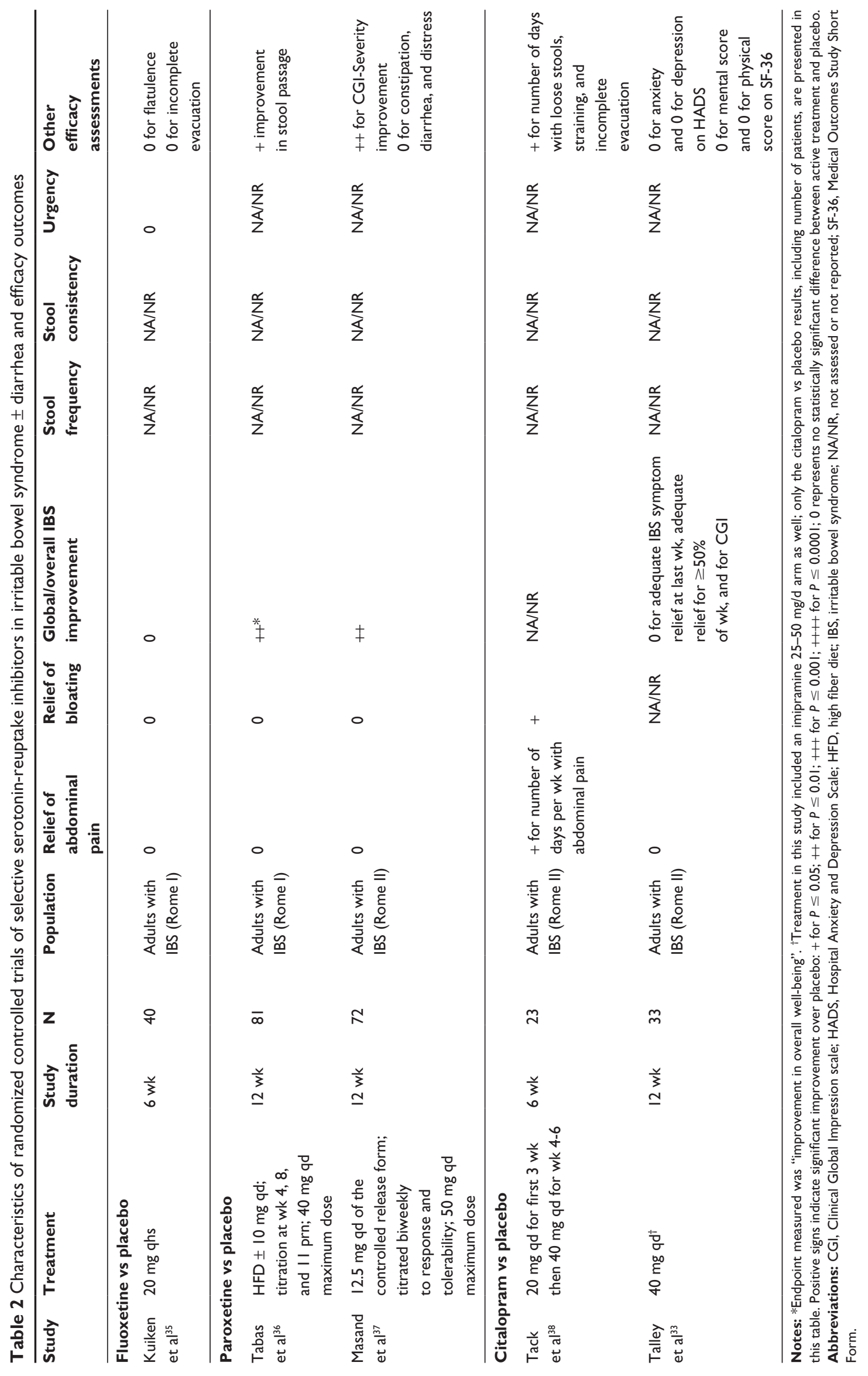


LHBT for determining SIBO has been controversial because of suboptimal specificity, leading to a high false-positive rate. ${ }^{40}$ However, other lines of evidence that implicate a role for altered bacteria in IBS pathophysiology include the strong temporal association between acute enteric infection and subsequent IBS symptoms, ${ }^{39,48}$ qualitative changes observed in the intestinal microbiota of IBS patients, ${ }^{41,49}$ evidence of low-grade inflammation in IBS patients (perhaps triggered by luminal bacteria ${ }^{50}$ ), and accumulating evidence of a therapeutic benefit of antibiotics and probiotics in IBS. $^{44,51,52}$

\section{Neomycin}

Pimentel et $\mathrm{al}^{21}$ investigated the effect of a 10-day course of neomycin or placebo on IBS symptoms in 111 patients meeting Rome I criteria for IBS. IBS-D was present in $41 \%$ of patients at baseline, while $34 \%$ of patients had IBS-C. The primary outcome was a composite symptom score that included scores for abdominal pain, diarrhea, and constipation. In the intention-to-treat analysis, neomycin achieved a greater reduction in the composite score than placebo $(35.0 \% \pm 5.0 \%$ vs $11.4 \% \pm 9.3 \%$ reduction, respectively; $P<0.05$ ); the reduction was also significant for neomycin in the subgroup of patients with abnormal baseline LHBT results $(P<0.01) .{ }^{21}$ Further, more patients treated with neomycin than with placebo achieved a $\geq 50 \%$ reduction in composite score (43\% vs $23 \%$, respectively; $P<0.05)$. Among the 41 neomycin-treated patients who had an abnormal LHBT finding at baseline, eight (20\%) had a normal LHBT result after treatment; this group experienced a greater improvement in symptoms than those whose LHBT result remained abnormal. Adverse events during the study were not adequately detailed to compare the two groups. $^{21}$

\section{Rifaximin}

Rifaximin, a nonabsorbable antibiotic with activity against gram-negative and gram-positive bacteria, as well as aerobic and anaerobic bacteria, ${ }^{53}$ is the most extensively studied medication in its class for IBS (Table 3). ${ }^{21,44,51,54-58}$ Studies published to date have randomized patients who met Rome I, ${ }^{44}$ Rome II, ${ }^{54-60}$ or a combination of Rome II IBS criteria and presentation with intestinal gas-related symptoms (bloating or excessive flatulence). ${ }^{51}$ One study limited enrollment to patients with IBS-D,${ }^{54-57}$ while the largest two trials evaluated patients with nonconstipated IBS. ${ }^{59,60}$ Overall, patients were to receive rifaximin or placebo for 10-14 days and be followed for 10-12 weeks thereafter.
Pimentel et $\mathrm{al}^{44}$ treated 87 patients with either rifaximin $400 \mathrm{mg}$ three times daily or placebo for 10 days with subsequent follow-up for 10 weeks. Results showed significant improvements in global symptoms of IBS ( $P=0.02$ vs placebo) and bloating $(P=0.01$ vs placebo) throughout the 10-week follow-up, although differences in relief of abdominal pain, diarrhea, and constipation between the two groups were not significant.

In a more recent, larger phase II study $(\mathrm{N}=388)$ reported only in abstracts to date, ${ }^{54-57}$ rifaximin $550 \mathrm{mg}$ twice daily or placebo was administered for 14 days to adults with IBS-D, defined by Rome II criteria, who were followed for 12 weeks. The rifaximin treatment group had a significantly higher percentage of patients than the placebo group with sustained global symptom improvement ( $52 \%$ vs $44 \%$, respectively; $P=0.03)$ and bloating $(46 \%$ vs $40 \% ; P=0.04)$ throughout the 12 weeks. $^{54}$ These improvements were more evident in patients with mild to moderate symptoms at baseline ${ }^{55}$ and, notably, rifaximin did not significantly improve global IBS symptoms or bloating versus placebo in patients with severe IBS symptoms. ${ }^{56}$ At 4 weeks, rifaximin significantly improved overall quality of life from baseline $(P=0.02) ;^{57}$ improvements in the individual domains of dysphoria, body image, health worry, social reaction, and relationship improvements were significant $(P<0.05$ for each) compared with placebo. Quality of life measures at the trial endpoint were not reported. ${ }^{57}$

Most recently, Pimentel et $\mathrm{al}^{22}$ reported results from two identically designed, multicenter, phase III, placebocontrolled trials (TARGET $1 \mathrm{~N}=623$; TARGET 2 $\mathrm{N}=637$; total $\mathrm{N}=1260$ ) in patients with nonconstipated IBS (defined by Rome II criteria) who were treated with rifaximin $550 \mathrm{mg}$ or placebo three times daily for 2 weeks and followed for an additional 10 weeks. Adequate relief of global IBS symptoms for at least 2 weeks of the first 4 weeks after treatment (the primary endpoint) was significant for rifaximin compared with placebo in both studies (TARGET $140.8 \%$ vs $31.2 \%$, respectively, $P=0.01$; TARGET $240.6 \%$ vs $32.2 \%$, respectively, $P=0.03$ ). Likewise, rifaximin treatment yielded a significantly greater rate of adequate relief of IBS-associated bloating over this same time period compared with placebo (TARGET $139.5 \%$ vs $28.7 \%, P=0.005$; TARGET $241.0 \%$ vs $31.9 \%, P=0.02$ ). Global symptom relief was also observed in both trials during follow-up, with the exception of relief of bloating in TARGET 1, where differences were significant between rifaximin- and placebo-treated patients for only the first 2 months. $^{22}$ 


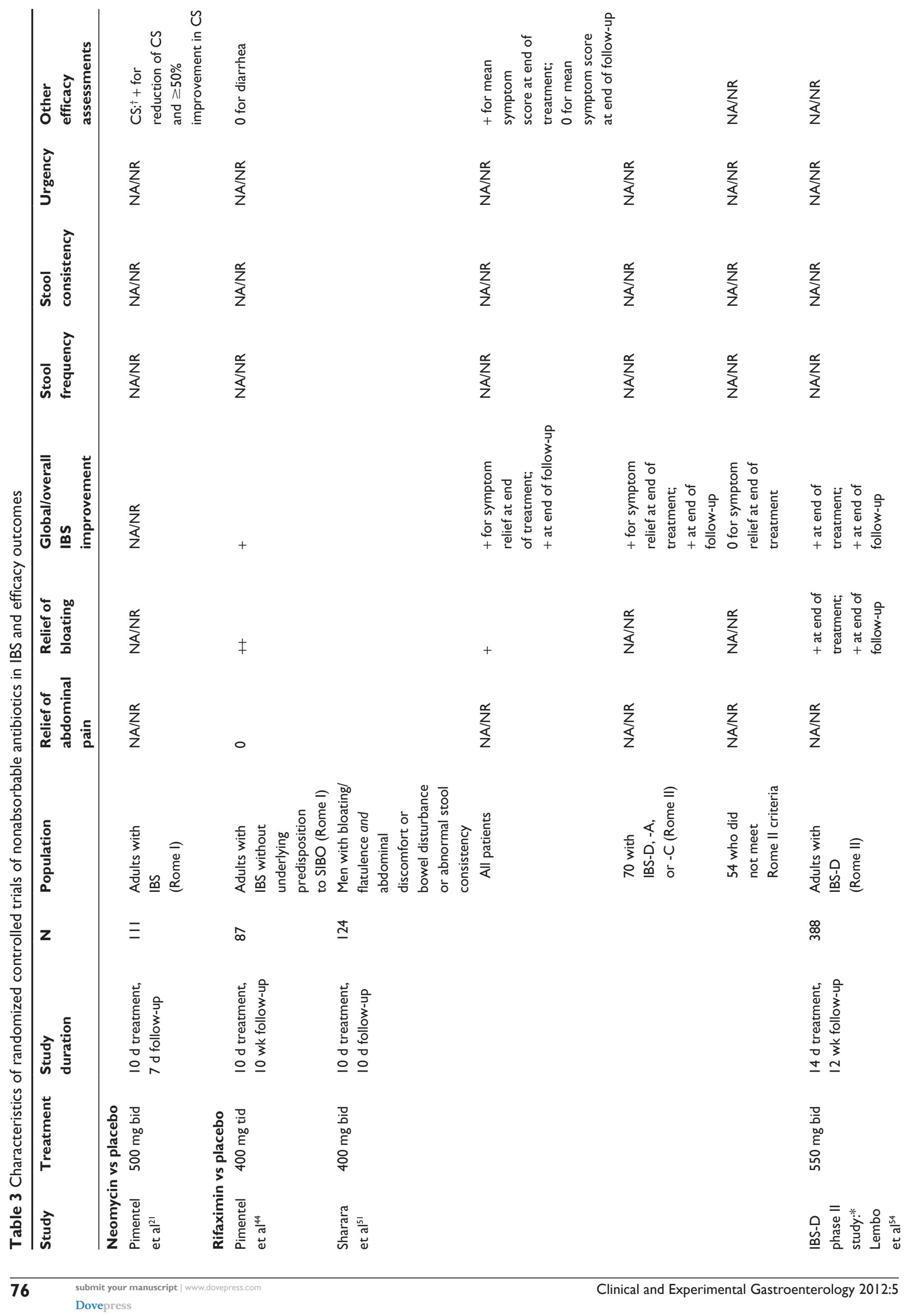




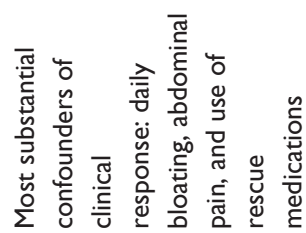

$\frac{\infty}{z}$

$\frac{\text { 妾 }}{z}$

产

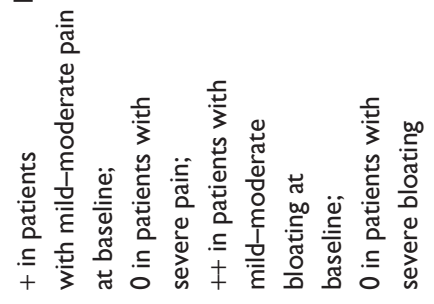

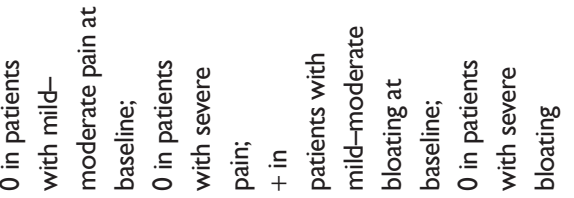

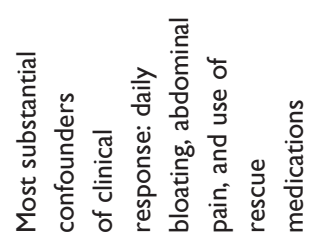

$\sum_{z}^{\frac{\alpha}{z}}$

$\frac{0}{z}$

产

등

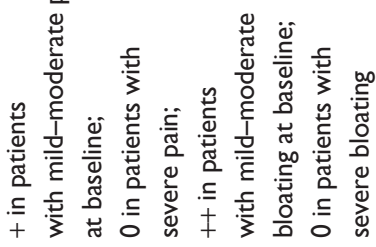

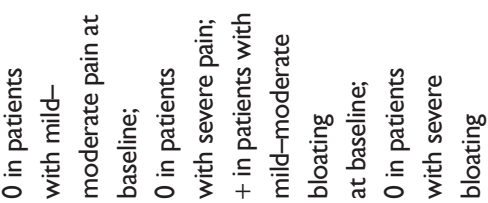

爰

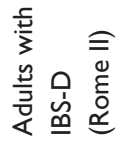

$\underset{\infty}{\infty}$

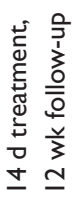

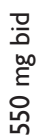

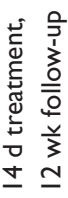

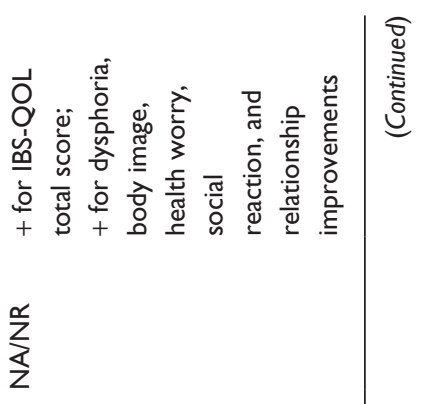

$\frac{o}{z}$

$\frac{0}{z}$

$\sum_{z}^{\frac{o}{x}}$

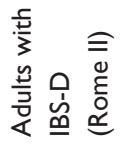

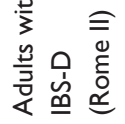

$\sum_{\substack{z \\ z}}^{\infty}$

$\frac{0}{z}$

$\stackrel{\infty}{\infty}$

$\stackrel{\infty}{m}$

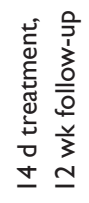

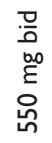

금
ao
है
ㅇํํ

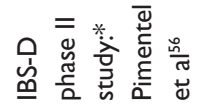

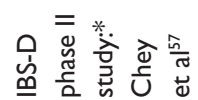




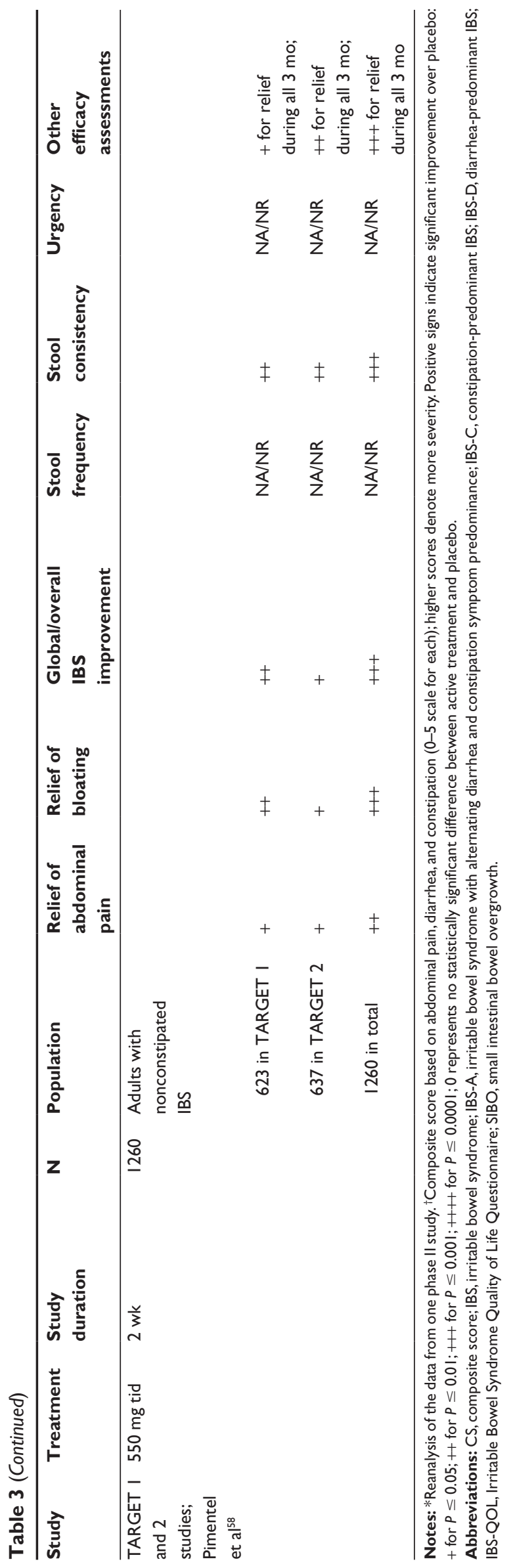

Overall, the safety profile of rifaximin appears similar to that of placebo. ${ }^{22,44}$ However, given the high prevalence of IBS in the general population, the chronic and recurrent nature of the disorder, and the potential for repeated use of antibiotics to treat this condition, induction of antibiotic resistance has been raised as a clinical issue that warrants further examination. ${ }^{61,62}$ Indeed, the new drug application for rifaximin submitted to the FDA for the indication of nonconstipated IBS was recently addressed in a complete response letter and was not approved with the data submitted; the FDA has requested additional data on retreatment with rifaximin in view of the hypothetical risk of antibiotic resistance with repeated courses. ${ }^{63}$

\section{Alosetron}

Alosetron is a selective 5- $\mathrm{HT}_{3}$ antagonist that is currently the only FDA-approved agent for IBS-D, specifically in women with severe IBS-D who have an inadequate response to conventional therapy. ${ }^{26}$ The efficacy of this medication in IBS is thought to result from selective antagonism of the $5-\mathrm{HT}_{3}$ receptor, leading to normalization of several key abnormalities implicated in the pathophysiology of IBS-D: GI motility, intestinal secretion, and pain perception or visceral hypersensitivity. ${ }^{910,18,19}$ Alosetron affects motor activity by slowing intestinal tract transit time ${ }^{24,64}$ and enhancing fluid reabsorption. Alosetron reduces sensation of IBS-related visceral pain by decreasing blood flow to the brain's emotional motor center ${ }^{23}$ by relaxing colonic tissue and altering the perception of distention in the abdomen. ${ }^{65}$

Numerous randomized controlled trials investigated the effect of alosetron on IBS (Table 4) ${ }^{66-75}$ Each of these studies enrolled at least 300 patients with IBS, with most enrolling more than 600 patients. Women made up approximately $84 \%$ of the overall clinical trial population. ${ }^{66-78}$ The diagnosis of IBS in these investigations was based on Rome I ${ }^{66-69,71,72,74,76}$ or Rome II ${ }^{70,73,75,77,78}$ criteria. Three of the more recent studies included women with nonconstipated IBS, IBS-D, or severe IBS-D, ${ }^{73,75,77,78}$ reflecting patient populations that are more consistent with the use of alosetron in the clinical practice setting. ${ }^{79}$

Review of the clinical data shows that alosetron has consistently demonstrated efficacy in producing significant relief of abdominal pain and discomfort compared with placebo. ${ }^{66-69,74,76,77}$ Camilleri et al ${ }^{66}$ found that alosetron $1 \mathrm{mg}$ and $2 \mathrm{mg}$ twice daily provided adequate relief of pain and discomfort in female patients with IBS significantly more often than placebo $(P<0.05) .{ }^{66}$ Likewise, Bardhan et al ${ }^{67}$ found that alosetron $2 \mathrm{mg}$ twice daily significantly increased the proportion of pain-free days in the total population $(P \leq 0.05)$, 
specifically in women $(P \leq 0.05)$. A later dose-ranging trial performed in men with IBS-D revealed that alosetron $1 \mathrm{mg}$ twice daily provided significantly more relief from IBS pain than placebo $(P=0.012)$, whereas no significant effect was seen with the dosages of $0.5 \mathrm{mg}, 2 \mathrm{mg}$, or $4 \mathrm{mg}$ twice daily. ${ }^{76}$ The most consistent and statistically significant effect of alosetron was on adequate relief of abdominal pain ${ }^{68,69,74,76,77}$ when given at a dosage of $1 \mathrm{mg}$ twice daily. This significant abdominal pain relief was observed in clinical trials typically of 12 weeks' duration, but benefits have also been demonstrated over the long term. Chey et $\mathrm{al}^{74}$ found that patients receiving alosetron had significantly greater 48 -week average adequate relief of pain than patients receiving placebo.

Alosetron has been shown to improve multiple other IBS symptom domains, and significant global symptom improvements on the Global Improvement Scale or by overall satisfaction ratings $(P<0.05 \text { for all })^{70,73,75,77}$ have been noted. Additionally, significant improvements in stool frequency ${ }^{66-70,74,75,77}$ and stool consistency ${ }^{66-70,74-77}$ were reported in several studies ( $P<0.05$ for all). One of the most bothersome IBS symptoms, fecal urgency, has been shown to be significantly improved with alosetron. ${ }^{66,68-70,74,75,77}$ In particular, when patients with severe bowel urgency symptoms (defined as lack of satisfactory control of urgency for at least 10 of 14 days during the trial screening phase) were assessed over 12 weeks of treatment, alosetron elicited significant improvement of urgency, as evidenced by the proportion of patients who achieved satisfactory control of urgency for a median $66 \%$ of days, compared with a median $43 \%$ of days in those receiving placebo $(P<0.001) .{ }^{75}$ Moreover, alosetron has been shown to improve the quality of life of IBS patients. ${ }^{71}$ Watson et al $^{71}$ reported statistically significant improvements from baseline in IBS-D in all nine domains of the IBS Quality of Life Questionnaire (emotional health, mental health, sleep, energy, physical functioning, food/ diet, social functioning, role-physical, and sexual relations) compared with placebo in one study $(n=626 ; P \leq 0.05$ for all nine) and in eight of nine domains in another study ( $n=647$; $P \leq 0.05$ for all eight).

Alosetron was generally well tolerated in clinical trials; however, it was associated with a greater incidence of constipation than placebo, which appeared to be dose related. ${ }^{66-70,72,74-77}$ Ischemic colitis (IC) and complications of constipation are known serious adverse events that have been associated with alosetron in clinical trials and postmarketing experience. ${ }^{76,77,80,81}$ In IBS clinical trials, the cumulative incidence of IC in women receiving alosetron was $0.2 \%$ through 3 months and $0.3 \%$ through 6 months. The incidence of serious complications of constipation was approximately $0.1 \%$ in women who were treated with either alosetron or placebo. ${ }^{26} \mathrm{~A}$ recent review of alosetron postmarketing safety data gathered over the past 5-6 years has shown that the incidence of IC and complications of constipation has been stable over time, and occurrences have remained rare since its reintroduction to the market in 2002 ( 0.36 and 0.95 cases per 1000 patient-years, respectively). ${ }^{81}$ Moreover, serious outcomes of these adverse events have been mitigated effectively with the alosetron prescribing program, with no cases of transfusions, surgeries, or deaths reported since the institution of the risk management program (now a Risk Evaluation and Mitigation Strategies [REMS] program). ${ }^{81}$

Despite several hypotheses that have been proposed to explain the association of alosetron and other serotonergic drugs with IC, the underlying pathophysiologic mechanism or mechanisms by which IC develops remain unknown. It is interesting to note that numerous epidemiologic studies using various methodologies have described an increased risk for the development of IC in patients with IBS. ${ }^{82-87}$ Across these studies, a diagnosis of IBS was associated with a 2-3.4 times increase in the odds of developing IC, bringing into question whether IC is part of the natural history of IBS. ${ }^{88}$

The ACG IBS Task Force classified the quality of evidence supporting the use of alosetron in IBS as high and has determined that alosetron is more effective than placebo at relieving global IBS symptoms in men and women with IBS-D. ${ }^{3}$ Given the risk of potentially serious side effects of IC and complications of constipation, the benefit:risk ratio for alosetron is most favorable in women who have not responded to conventional therapies, and indeed this is the population for which alosetron is indicated.

\section{Discussion}

Evidence for the use of the TCAs, antibiotics, and the 5- $\mathrm{HT}_{3}$ antagonist alosetron in patients with IBS and IBS-D indicates that these agents are effective for the treatment of multiple symptoms operant in the IBS patient. The 2009 ACG IBS Task Force has recognized these options as the treatment strategies with the strongest evidence supporting their use in this population. ${ }^{3}$ Rather than being one-dimensional treatments, each of the highlighted classes or agents described has the potential to modulate an underlying pathophysiologic mechanism believed to cause IBS, in contrast to conventional agents that are often prescribed but not FDA approved specifically for IBS-D.

The TCAs are thought to act on visceral hypersensitivity by increasing pain thresholds and may act peripherally as well to slow gut transit times. ${ }^{3,27}$ TCA studies in IBS are few in number and include small patient populations, but 


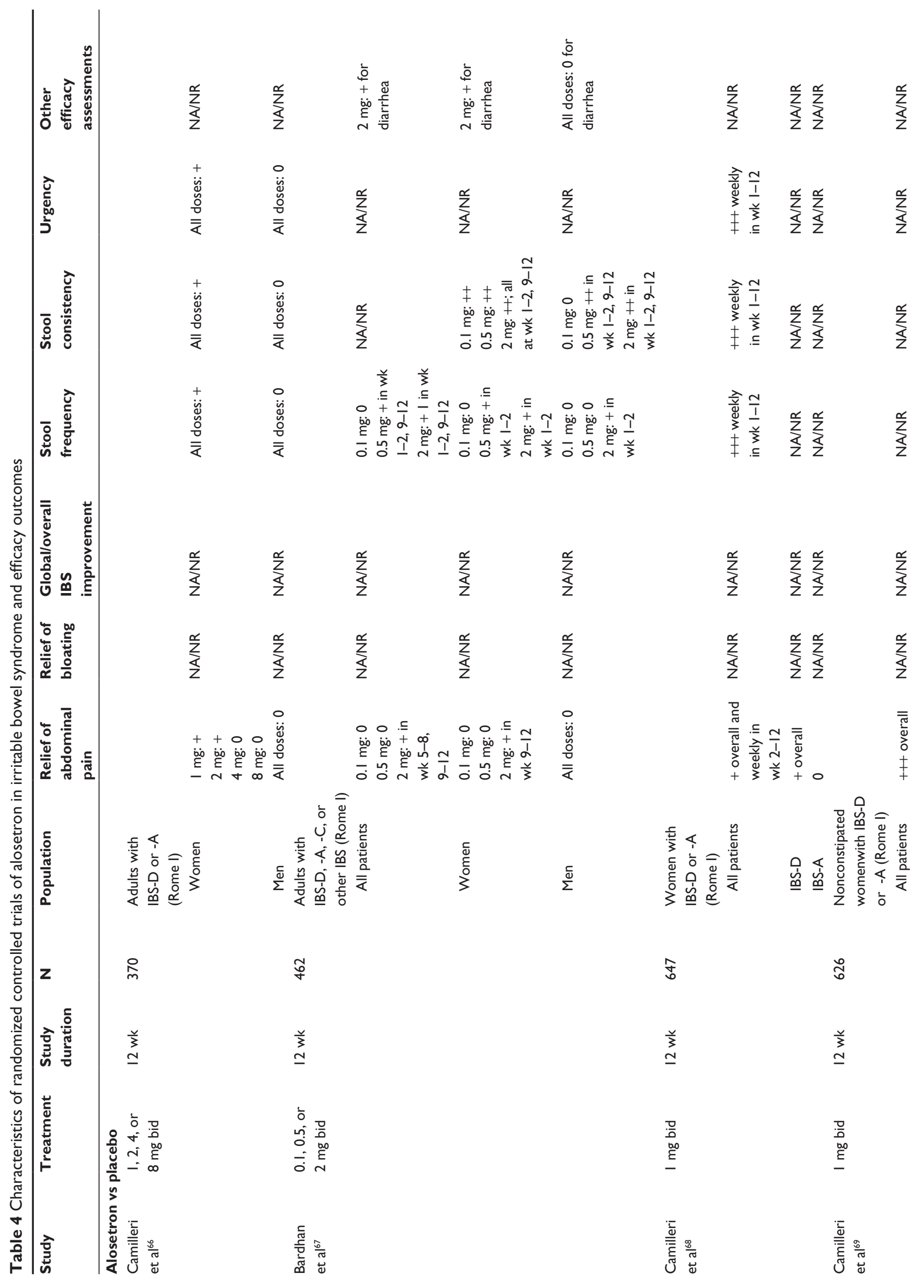




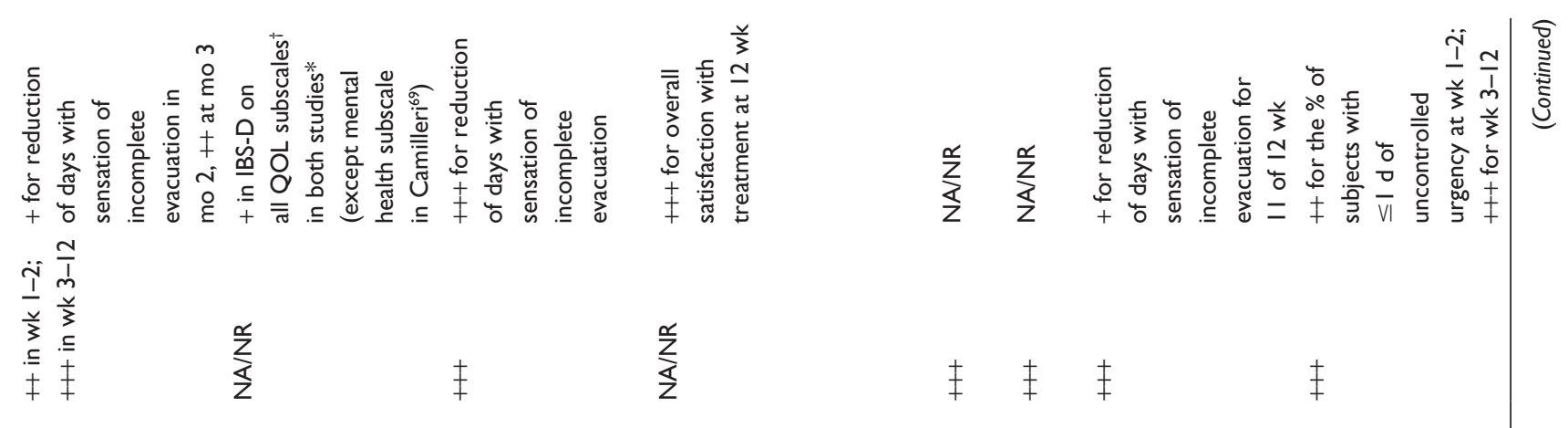

$$
=\frac{+}{\frac{1}{3}}
$$

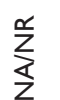

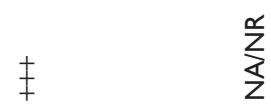

$\underset{\frac{\infty}{z}}{\frac{\infty}{z}}$

$\stackrel{1}{1}$
$\frac{1}{3}$
$\stackrel{5}{ \pm}$
\pm
+

$\underset{z}{\frac{0}{z}}$

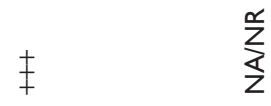

$\underset{z}{\stackrel{x}{z}}$

兴旁文

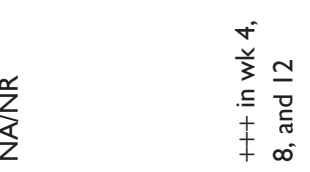

产

$\ddagger \quad \ddagger \quad$

$\ddagger$

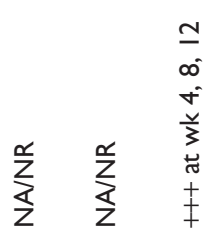

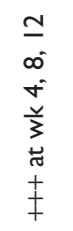

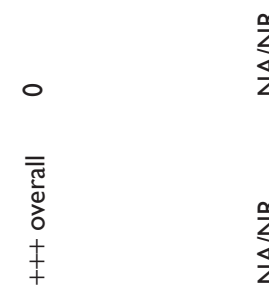

旁

$\sum_{z}^{\frac{0}{z}}$

$\underset{z}{\frac{c}{z}}$

首旁

$\sum_{z}^{\frac{\alpha}{z}} \frac{o}{z}$

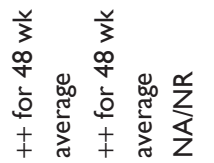

$\ddagger$

$\sum_{z}^{\frac{\alpha}{z}} \quad \frac{\alpha}{z}$

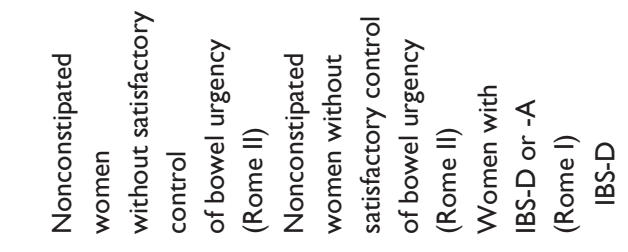

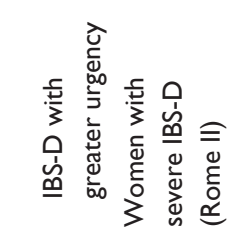

$\frac{\alpha}{z}$

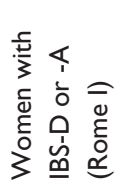

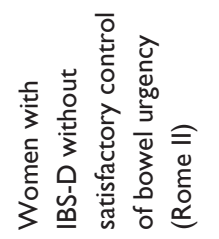

$\stackrel{\mathfrak{a}}{\underline{a}}$

$\bar{\infty}$

$\bar{\infty}$

$\frac{\nabla}{N}$

d

$\bar{N}$

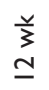

$\stackrel{5}{3}$

$\stackrel{5}{3}$

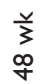

$\stackrel{\text { ㄴ. }}{\leq}$

$\stackrel{0}{\overline{0}}$
$\stackrel{0}{00}$
$\underline{-}$

$\frac{}{0}$
o0
$\underline{E}$

$\frac{0}{\bar{O}}$
bo
$\underline{E}$

$\frac{0}{0}$
bo
$\underline{\varepsilon}$

$\stackrel{ }{0}$
bo
$\underline{E}$

总

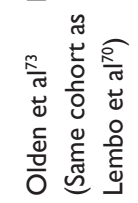

ํㅝㄹ

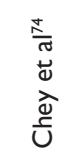

可 


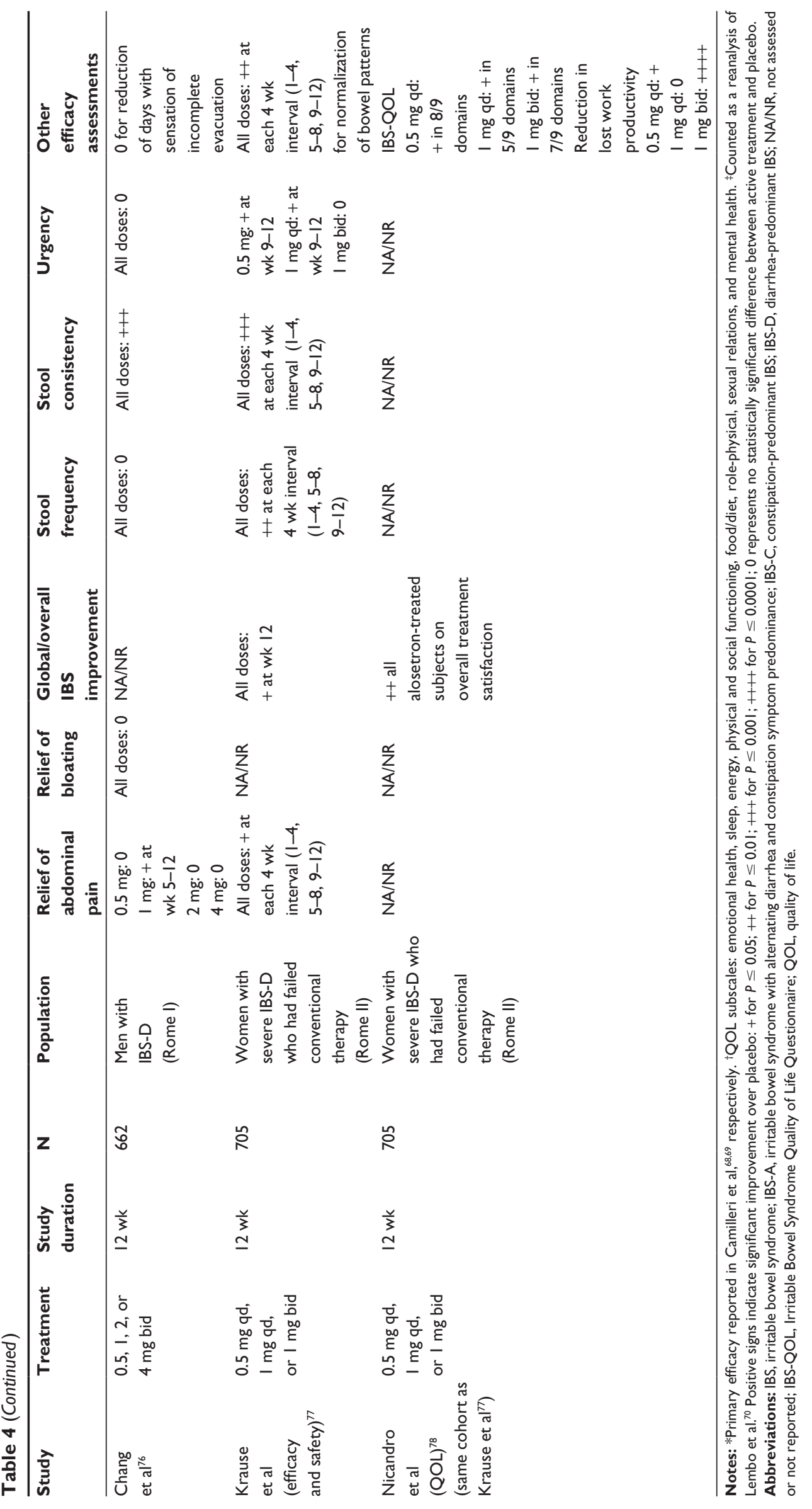


amitriptyline $e^{28,29}$ and desipramine ${ }^{30,31}$ appear to be effective for global IBS symptom relief. The capacity of these agents to reduce abdominal pain is less clear. The largest study of any of the TCAs is an investigation of desipramine. ${ }^{31}$ However, in this study, interpretation of the efficacy of desipramine was compromised by high patient withdrawals and noncompliance, although results showed it was effective in those patients who were able to tolerate it. The other TCA reviewed here, imipramine $25-50 \mathrm{mg}$ /day, did not show efficacy in IBS but was evaluated in only two small-scale studies. ${ }^{32,33}$ This agent may be effective in larger patient populations and perhaps at higher doses. Overall, the reported efficacy of the TCAs in the control of stool frequency and consistency has varied. ${ }^{28-30}$ The tolerability of the TCAs depends largely on the propensity of these agents to exert cholinergic, histaminergic, and adrenergic side effects, ${ }^{16}$ which indeed may affect adherence. Additionally, the prescriber must also be cognizant that the TCAs can be associated with death in overdose, ${ }^{34}$ especially in light of suicidal ideation findings that were related purely to IBS symptoms in secondary and tertiary care patients observed by Miller et al. ${ }^{34}$

Evidence that antibiotics show a therapeutic benefit in IBS has been evaluated and scrutinized for many years; however, the role of antibiotics in the management of IBS remains undefined, owing in part to uncertainty about the association between altered intestinal flora and IBS pathogenesis. Study findings suggesting differences in the gut microbiota between IBS sufferers and healthy controls $^{41,49}$ have been inconsistent, and the relative contributions of the various altered bacterial populations to IBS physiology and symptom development have not been determined ${ }^{89}$ Likewise, the link between SIBO and IBS symptoms remains controversial, particularly because of the wide variability in reported prevalence rates of SIBO in IBS patients (most studies report a 10\% prevalence, whereas Pimentel et $\mathrm{al}^{21}$ have a reported prevalence as high as $84 \%$ ), and the lack of sensitivity and specificity of breath testing methods (ie, lactulose, glucose, sucrose) for diagnosing SIBO. ${ }^{40,45,90,91}$ Indeed, in the single study that used direct aspiration and culture of jejunal secretions to assess SIBO, no difference in the prevalence of SIBO (defined as $\geq 10^{5} \mathrm{cfu} / \mathrm{mL}$ ) was found between IBS patients and controls. ${ }^{92}$ Additionally, a retrospective cohort study by Chan et a ${ }^{93}$ found that only $32 \%$ of those receiving an antibiotic course for SIBO realized a complete symptomatic response. Interestingly, the IBS condition was found to be an independent risk factor for an incomplete response to antibiotics using multivariate regression analysis. Most recently, Yu et $\mathrm{a}^{45}$ found that the abnormal rise in $\mathrm{H}_{2}$ measured by the LHBT appears to be explained by variations in orocecal transit time in patients with IBS and not by the presence of SIBO.

Acute clinical trials of rifaximin in nonconstipated IBS have provided evidence of global symptom improvements and bloating relief. ${ }^{44,51,54-60}$ At present, it is not clear if rifaximin can provide durable effects beyond 3 months, if it provides relief in patients with severe symptoms, or if repetitive treatment would lead to antibiotic resistance. Longer-term studies of rifaximin are necessary to support its use in IBS.

Alosetron is the only FDA-approved agent for use in women with severe IBS-D. Its proposed mechanism of action involves targeting the 5- $\mathrm{HT}_{3}$ serotonin receptor subtype known to play a role in influencing GI motility, intestinal secretion, and pain perception or visceral hypersensitivity., ${ }^{9,10,18,19}$ Alosetron is effective for relieving global IBS symptoms $\mathrm{s}^{70,73,75,77}$ and abdominal pain/discomfort, ${ }^{66-69,74,76,77}$ as well as multiple other symptom domains, including stool frequency, ${ }^{66-70,74,75,77}$ stool consistency, ${ }^{66-70,74-77}$ and fecal urgency, ${ }^{66,68-70,74,75,77}$ for up to 1 year of treatment. Likewise, alosetron improves quality of life in IBS patients. ${ }^{71,78}$ Institution of the REMS program upon the market reintroduction of alosetron has provided health care providers and patients with a valuable tool allowing proper patient selection. The potential for side effects of constipation and IC are predictable and well understood such that complications from either of these adverse events have been mitigated to the point of being virtually nonexistent since the REMS program was initiated. ${ }^{81}$ Alosetron represents a viable and highly effective therapeutic option in women with severe IBS-D, providing multisymptom relief, a well-characterized tolerability profile, and improvements in quality of life.

\section{Conclusion}

High-quality placebo-controlled clinical evidence of efficacy in IBS is available for TCAs, antibiotics, and alosetron. Depending on the nature of the symptoms in the individual patient with IBS, each of these targeted therapies is able to provide benefit that goes beyond the monosymptomatic relief conferred by conventional therapies. Knowledge of the differential treatment effects of each of these agents may facilitate development of a more personalized treatment approach in IBS. Despite current and emerging evidence, alosetron remains the only therapeutic option that is FDA approved for the treatment of IBS-D. As new therapies are investigated, the effects of specific agents on multitiered patient-reported outcome measures (as are now recommended by the FDA $)^{94}$ will be informative to the field and 
will help shape future evidence-based practice guidelines for the treatment of IBS.

\section{Acknowledgments}

The authors thank John H Simmons, MD, and Peloton Advantage, LLC, for their editorial assistance in preparing this manuscript, which was funded by Prometheus Laboratories. The author is fully responsible for all content, editorial decisions, and opinions expressed in this paper.

\section{Disclosure}

The author has received research grants from Prometheus Laboratories and is on the speakers' bureaus of Salix Laboratories and Prometheus Laboratories.

\section{References}

1. Saito YA, Schoenfeld P, Locke GR III. The epidemiology of irritable bowel syndrome in North America: a systematic review. Am J Gastroenterol. 2002;97:1910-1915.

2. Hungin AP, Chang L, Locke GR, Dennis EH, Barghout V. Irritable bowel syndrome in the United States: prevalence, symptom patterns and impact. Aliment Pharmacol Ther. 2005;21:1365-1375.

3. American College of Gastroenterology Task Force on Irritable Bowel Syndrome. An evidence-based position statement on the management of irritable bowel syndrome. Am J Gastroenterol. 2009;104 Suppl 1: S1-S35.

4. Andrews EB, Eaton SC, Hollis KA, et al. Prevalence and demographics of irritable bowel syndrome: results from a large Web-based survey. Aliment Pharmacol Ther. 2005;22:935-942.

5. International Foundation for Functional Gastrointestinal Disorders. IBS in the Real World Survey. Summary findings. Website. 2007. Available from: http://aboutconstipation.org/pdfs/IBSRealWorld.pdf. Accessed February 3, 2012.

6. El-Serag HB, Olden K, Bjorkman D. Health-related quality of life among persons with irritable bowel syndrome: a systematic review. Aliment Pharmacol Ther. 2002;16:1171-1185.

7. Gralnek IM, Hays RD, Kilbourne A, Naliboff B, Mayer EA. The impact of irritable bowel syndrome on health-related quality of life. Gastroenterology. 2000;119:654-660.

8. Drossman DA, Camilleri M, Mayer EA, Whitehead WE. AGA technical review on irritable bowel syndrome. Gastroenterology. 2002;123:2108-2131.

9. Sikander A, Rana SV, Prasad KK. Role of serotonin in gastrointestinal motility and irritable bowel syndrome. Clin Chim Acta. 2009;403:47-55.

10. Gershon MD, Tack J. The serotonin signaling system: from basic understanding to drug development for functional GI disorders. Gastroenterology. 2007;132:397-414.

11. Dunlop SP, Coleman NS, Blackshaw E, et al. Abnormalities of 5-hydroxytryptamine metabolism in irritable bowel syndrome. Clin Gastroenterol Hepatol. 2005;3:349-357.

12. Atkinson W, Lockhart S, Whorwell PJ, Keevil B, Houghton LA. Altered 5-hydroxytryptamine signaling in patients with constipationand diarrhea-predominant irritable bowel syndrome. Gastroenterology. 2006;130:34-43.

13. Clarke G, Quigley EM, Cryan JF, Dinan TG. Irritable bowel syndrome: towards biomarker identification. Trends Mol Med. 2009;15:478-489.

14. Saad RJ, Chey WD. Recent developments in the therapy of irritable bowel syndrome. Expert Opin Investig Drugs. 2008;17:117-130.

15. Mayer EA. Clinical practice. Irritable bowel syndrome. $N$ Engl J Med. 2008;358:1692-1699.
16. Lacy BE, Weiser K, De Lee R. Review: the treatment of irritable bowel syndrome. Therap Adv Gastroenterol. 2009;2:221-238.

17. Gorard DA, Libby GW, Farthing MJ. Influence of antidepressants on whole gut and orocaecal transit times in health and irritable bowel syndrome. Aliment Pharmacol Ther. 1994;8:159-166.

18. Crowell MD. The role of serotonin in the pathophysiology of irritable bowel syndrome. Am J Manag Care. 2001;7 Suppl:S252-S260.

19. Baker DE. Rationale for using serotonergic agents to treat irritable bowel syndrome. Am J Health Syst Pharm. 2005;62:700-711.

20. Lin HC. Small intestinal bacterial overgrowth: a framework for understanding irritable bowel syndrome. JAMA. 2004;292:852-858.

21. Pimentel M, Chow EJ, Lin HC. Normalization of lactulose breath testing correlates with symptom improvement in irritable bowel syndrome. a double-blind, randomized, placebo-controlled study. Am $J$ Gastroenterol. 2003;98:412-419.

22. Pimentel M, Lembo A, Chey WD, et al. Rifaximin therapy for patients with irritable bowel syndrome without constipation. $N$ Engl $J$ Med. 2011;364:22-32.

23. Mayer EA, Berman S, Derbyshire SW, et al. The effect of the 5-HT receptor antagonist, alosetron, on brain responses to visceral stimulation in irritable bowel syndrome patients. Aliment Pharmacol Ther. 2002;16:1357-1366.

24. Houghton LA, Foster JM, Whorwell PJ. Alosetron, a 5-HT 3 receptor antagonist, delays colonic transit in patients with irritable bowel syndrome and healthy volunteers. Aliment Pharmacol Ther. 2000;14:775-782.

25. Johanson JF. Options for patients with irritable bowel syndrome: contrasting traditional and novel serotonergic therapies. Neurogastroenterol Motil. 2004;16:701-711.

26. Lotronex ${ }^{\circledR}$ (alosetron hydrochloride) tablets [package insert]. San Diego, CA: Prometheus Laboratories Inc; 2010.

27. Ford AC, Talley NJ, Schoenfeld PS, Quigley EM, Moayyedi P. Efficacy of antidepressants and psychological therapies in irritable bowel syndrome: systematic review and meta-analysis. Gut. 2009;58:367-378.

28. Rajagopalan M, Kurian G, John J. Symptom relief with amitriptyline in the irritable bowel syndrome. $J$ Gastroenterol Hepatol. 1998;13:738-741.

29. Vahedi H, Merat S, Momtahen S, et al. Clinical trial: the effect of amitriptyline in patients with diarrhoea-predominant irritable bowel syndrome. Aliment Pharmacol Ther. 2008;27:678-684.

30. Greenbaum DS, Mayle JE, Vanegeren LE, et al. Effects of desipramine on irritable bowel syndrome compared with atropine and placebo. Dig Dis Sci. 1987;32:257-266.

31. Drossman DA, Toner BB, Whitehead WE, et al. Cognitive-behavioral therapy versus education and desipramine versus placebo for moderate to severe functional bowel disorders. Gastroenterology. 2003;125:19-31.

32. Abdul-Baki H, El Hajj II, Elzahabi L, et al. A randomized controlled trial of imipramine in patients with irritable bowel syndrome. World $J$ Gastroenterol. 2009;15:3636-3642.

33. Talley NJ, Kellow JE, Boyce P, Tennant C, Huskic S, Jones M. Antidepressant therapy (imipramine and citalopram) for irritable bowel syndrome: a double-blind, randomized, placebo-controlled trial. Dig Dis Sci. 2008;53:108-115.

34. Miller V, Hopkins L, Whorwell PJ. Suicidal ideation in patients with irritable bowel syndrome. Clin Gastroenterol Hepatol. 2004;2:1064-1068.

35. Kuiken SD, Tytgat GN, Boeckxstaens GE. The selective serotonin reuptake inhibitor fluoxetine does not change rectal sensitivity and symptoms in patients with irritable bowel syndrome: a double blind, randomized, placebo-controlled study. Clin Gastroenterol Hepatol. 2003;1:219-228.

36. Tabas G, Beaves M, Wang J, Friday P, Mardini H, Arnold G. Paroxetine to treat irritable bowel syndrome not responding to high-fiber diet: a doubleblind, placebo-controlled trial. Am J Gastroenterol. 2004;99:914-920.

37. Masand PS, Pae CU, Krulewicz S, et al. A double-blind, randomized, placebo-controlled trial of paroxetine controlled-release in irritable bowel syndrome. Psychosomatics. 2009;50:78-86. 
38. Tack J, Broekaert D, Fischler B, Van Oudenhove L, Gevers AM, Janssens J. A controlled crossover study of the selective serotonin reuptake inhibitor citalopram in irritable bowel syndrome. Gut. 2006;55: 1095-1103.

39. Marshall JK, Thabane M, Garg AX, Clark WF, Salvadori M, Collins SM. Incidence and epidemiology of irritable bowel syndrome after a large waterborne outbreak of bacterial dysentery. Gastroenterology. 2006;131:445-450.

40. Ford AC, Spiegel BM, Talley NJ, Moayyedi P. Small intestinal bacterial overgrowth in irritable bowel syndrome: systematic review and meta-analysis. Clin Gastroenterol Hepatol. 2009;7: 1279-1286.

41. Malinen E, Rinttila T, Kajander K, et al. Analysis of the fecal microbiota of irritable bowel syndrome patients and healthy controls with real-time PCR. Am J Gastroenterol. 2005;100:373-382.

42. Frissora CL, Cash BD. Review article: the role of antibiotics vs conventional pharmacotherapy in treating symptoms of irritable bowel syndrome. Aliment Pharmacol Ther. 2007;25:1271-1281.

43. Pimentel M, Chow EJ, Lin HC. Eradication of small intestinal bacterial overgrowth reduces symptoms of irritable bowel syndrome. Am J Gastroenterol. 2000;95:3503-3506.

44. Pimentel M, Park S, Mirocha J, Kane SV, Kong Y. The effect of a nonabsorbed oral antibiotic (rifaximin) on the symptoms of the irritable bowel syndrome: a randomized trial. Ann Intern Med. 2006;145:557-563.

45. Yu D, Cheeseman F, Vanner S. Combined oro-caecal scintigraphy and lactulose hydrogen breath testing demonstrate that breath testing detects oro-caecal transit, not small intestinal bacterial overgrowth in patients with IBS. Gut. 2011;60:334-340.

46. Spiegel BMR. Questioning the bacterial overgrowth hypothesis of irritable bowel syndrome: an epidemiologic and evolutionary perspective. Clin Gastroenterol Hepatol. 2011;9:461-469.

47. Walters B, Vanner SJ. Detection of bacterial overgrowth in IBS using the lactulose $\mathrm{H} 2$ breath test: comparison with 14C-D-xylose and healthy controls. Am J Gastroenterol. 2005;100:1566-1570.

48. Halvorson HA, Schlett CD, Riddle MS. Postinfectious irritable bowel syndrome - a meta-analysis. Am J Gastroenterol. 2006;101:1894-1899.

49. Kassinen A, Krogius-Kurikka L, Makivuokko H, et al. The fecal microbiota of irritable bowel syndrome patients differs significantly from that of healthy subjects. Gastroenterology. 2007;133: 24-33.

50. Quigley EM. What is the evidence for the use of probiotics in functional disorders? Curr Gastroenterol Rep. 2008;10:379-384.

51. Sharara AI, Aoun E, Abdul-Baki H, Mounzer R, Sidani S, Elhajj I A randomized double-blind placebo-controlled trial of rifaximin in patients with abdominal bloating and flatulence. Am J Gastroenterol. 2006;101:326-333.

52. Moayyedi P, Duffett S, Mason S, Brown J, Axon ATR. The influence of antibiotics on irritable bowel syndrome: a randomised controlled trial [abstract T1487]. Gastroenterology. 2002;122 Suppl 4:A465.

53. Jiang ZD, DuPont HL. Rifaximin: in vitro and in vivo antibacterial activity - a review. Chemotherapy. 2005;51 Suppl 1:67-72.

54. Lembo A, Zakko SF, Ferreira NL, et al. Rifaximin for the treatment of diarrhea associated irritable bowel syndrome: short term treatment leading to long term sustained response [abstract T1390]. Gastroenterology. 2008;134 Suppl 1:A545.

55. Ringel Y, Palsson OS, Zakko SF. Predictors of clinical response from a hase 2 multi-center efficacy trial using rifaximin, a gut-selective, non-absorbed antibiotic for the treatment of diarrhea associated irritable bowel syndrome [abstract T1411]. Gastroenterology. 2008;134 Suppl. 1:A550

56. Pimentel M, Ringel Y, Brooks C, Bortey E, Forbes W. Severity of irritable bowel syndrome-related symptoms predicts clinical response to the nonsystemic antibiotic rifaximin [abstract P1065]. Presented at the 73rd annual meeting of the American College of Gastroenterology; October 3-8, 2008; Orlando, FL.
57. Chey WD, Talley NJ, Lembo A, Yu A, Bortey E. Rifaximin significantly improves quality of life versus placebo in patients with diarrheapredominant irritable bowel syndrome [abstract P691]. Presented at the 73rd annual meeting of the American College of Gastroenterology; October 3-8, 2008; Orlando, FL.

58. Pimentel M, Lembo A, Chey WD, et al. Rifaximin treatment for 2 weeks provides acute and sustained relief over 12 weeks of IBS symptoms in non-constipated irritable bowel syndrome: results from 2 North American phase 3 trials (Target 1 and Target 2) [abstract 475i]. Gastroenterology. 2010;138:S-64-S-65.

59. Clinicaltrials.gov Identifier: NCT00731679. Rifaximin TID for nonconstipation irritable bowel syndrome (IBS) (Target 1). National Institutes of Health; 2009. Available from: http:/clinicaltrials.gov/ ct $2 /$ show/NCT000731679?term=Rifaximin\&rank=12. Accessed February 3, 2012.

60. Clinicaltrials.gov identifier: NCT00724126. Rifaximin 3 times/day for non-constipation IBS (Target 2). US National Institutes of Health; 2009. Available from: http:/clinicaltrials.gov/ct2/show/NCT00724126?term $=$ rifaximin\&rank=11. Accessed February 3, 2012.

61. Drossman DA. Treatment for bacterial overgrowth in the irritable bowel syndrome. Ann Intern Med. 2006;145:626-628.

62. Tack J. Antibiotic therapy for the irritable bowel syndrome. $N$ Engl J Med. 2011;364:81-82.

63. Salix receives anticipated FDA complete response letter on XIFAXAN ${ }^{\circledR}$ $500 \mathrm{mg}$ tablets Non-C IBS Supplemental New Drug Application. Salix Pharmaceuticals, Inc; 2011. Available from: http://www.salix. $\mathrm{com} /$ news-media/news/index/salix-receives-anticipated-fda-completeresponse-letter-on-xifaxan ${ }^{\circledR}$-550-mg-tablets-non-c-ibs-supplementalnew-drug-application.aspx. Accessed February 3, 2012.

64. Viramontes BE, Camilleri M, McKinzie S, Pardi DS, Burton D, Thomforde GM. Gender-related differences in slowing colonic transit by a 5-HT3 antagonist in subjects with diarrhea-predominant irritable bowel syndrome. Am J Gastroenterol. 2001;96:2671-2676.

65. Delvaux M. Role of visceral sensitivity in the pathophysiology of irritable bowel syndrome. Gut. 2002;51 Suppl 1:i67-i71.

66. Camilleri M, Mayer EA, Drossman DA, et al. Improvement in pain and bowel function in female irritable bowel patients with alosetron, a 5- $\mathrm{HT}_{3}$ receptor antagonist. Aliment Pharmacol Ther. 1999;13:1149-1159.

67. Bardhan KD, Bodemar G, Geldof $\mathrm{H}$, et al. A double-blind, randomized, placebo-controlled dose-ranging study to evaluate the efficacy of alosetron in the treatment of irritable bowel syndrome. Aliment Pharmacol Ther. 2000;14:23-34.

68. Camilleri M, Northcutt AR, Kong S, Dukes GE, McSorley D, Mangel AW. Efficacy and safety of alosetron in women with irritable bowel syndrome: a randomised, placebo-controlled trial. Lancet. 2000;355:1035-1040.

69. Camilleri M, Chey WY, Mayer EA, et al. A randomized controlled clinical trial of the serotonin type 3 receptor antagonist alosetron in women with diarrhea-predominant irritable bowel syndrome. Arch Intern Med. 2001;161:1733-1740.

70. Lembo T, Wright RA, Bagby B, et al. Alosetron controls bowel urgency and provides global symptom improvement in women with diarrhea-predominant irritable bowel syndrome. Am J Gastroenterol. 2001;96:2662-2670.

71. Watson ME, Lacey L, Kong S, et al. Alosetron improves quality of life in women with diarrhea-predominant irritable bowel syndrome. Am J Gastroenterol. 2001;96:455-459.

72. Wolfe SG, Chey WY, Washington MK, et al. Tolerability and safety of alosetron during long-term administration in female and male irritable bowel syndrome patients. Am J Gastroenterol. 2001;96: 803-811.

73. Olden K, DeGarmo RG, Jhingran P, et al. Patient satisfaction with alosetron for the treatment of women with diarrhea-predominant irritable bowel syndrome. Am J Gastroenterol. 2002;97:3139-3146.

74. Chey WD, Chey WY, Heath AT, et al. Long-term safety and efficacy of alosetron in women with severe diarrhea-predominant irritable bowel syndrome. Am J Gastroenterol. 2004;99:2195-2203. 
75. Lembo AJ, Olden KW, Ameen VZ, Gordon SL, Heath AT, Carter EG. Effect of alosetron on bowel urgency and global symptoms in women with severe, diarrhea-predominant irritable bowel syndrome: analysis of two controlled trials. Clin Gastroenterol Hepatol. 2004;2: 675-682.

76. Chang L, Ameen VZ, Dukes GE, McSorley DJ, Carter EG, Mayer EA. A dose-ranging, phase II study of the efficacy and safety of alosetron in men with diarrhea-predominant IBS. Am J Gastroenterol. 2005;100:115-123.

77. Krause R, Ameen V, Gordon SH, et al. A randomized, double-blind, placebo-controlled study to assess efficacy and safety of $0.5 \mathrm{mg}$ and $1 \mathrm{mg}$ alosetron in women with severe diarrhea-predominant IBS. Am J Gastroenterol. 2007;102:1709-1719.

78. Nicandro JPA, Shin P, Shringarpure R, Chuang E, Pan H. Alosetron is associated with improvements in treatment satisfaction and quality of life [abstract M1058]. Presented at Digestive Disease Week 2010; May 1-5, 2010; New Orleans, LA.

79. Miller D, Bennett L, Hollis K, Tennis P, Cook S, Andrews E. A patient follow-up survey programme for alosetron: assessing compliance to and effectiveness of the risk management programme. Aliment Pharmacol Ther. 2006;24:869-878.

80. Chang L, Chey WD, Harris L, Olden K, Surawicz C, Schoenfeld P. Incidence of ischemic colitis and serious complications of constipation among patients using alosetron: systematic review of clinical trials and post-marketing surveillance data. Am J Gastroenterol. 2006;101:1069-1079.

81. Chang L, Tong K, Ameen V. Ischemic colitis and complications of constipation associated with the use of alosetron under a risk management plan: clinical characteristics, outcomes, and incidences. Am J Gastroenterol. 2010;105:866-875.

82. Chang L, Kahler KH, Sarawate C, Quimbo R, Kralstein J. Assessment of potential risk factors associated with ischaemic colitis. Neurogastroenterol Motil. 2008;20:36-42.

83. Cole JA, Cook SF, Sands BE, Ajene AN, Miller DP, Walker AM. Occurrence of colon ischemia in relation to irritable bowel syndrome. Am J Gastroenterol. 2004;99:486-491.
84. Longstreth GF, Yao JF. Diseases and drugs that increase risk of acute large bowel ischemia. Clin Gastroenterol Hepatol. 2010;8: 49-54.

85. Singh G, Mithal A, Triadafilopoulos G. Patients with irritable bowel syndrome have a high-risk of developing ischemic colitis [abstract 349]. Gastroenterology. 2004;126:A41.

86. Suh DC, Kahler KH, Choi IS, Shin H, Kralstein J, Shetzline M. Patients with irritable bowel syndrome or constipation have an increased risk for ischaemic colitis. Aliment Pharmacol Ther. 2007;25:681-692.

87. Walker AM, Bohn RL, Cali C, Cook SF, Ajene AN, Sands BE. Risk factors for colon ischemia. Am J Gastroenterol. 2004;99:1333-1337.

88. Lewis JH. The risk of ischaemic colitis in irritable bowel syndrome patients treated with serotonergic therapies. Drug Saf. 2011;34:545-565.

89. Ringel Y, Carroll IM. Alterations in the intestinal microbiota and functional bowel symptoms. Gastrointest Endosc Clin North Am. 2009;19:141-150, vii.

90. Corazza GR, Menozzi MG, Strocchi A, et al. The diagnosis of small bowel bacterial overgrowth. Reliability of jejunal culture and inadequacy of breath hydrogen testing. Gastroenterology. 1990;98:302-309.

91. Riordan SM, McIver CJ, Walker BM, Duncombe VM, Bolin TD, Thomas MC. The lactulose breath hydrogen test and small intestinal bacterial overgrowth. Am J Gastroenterol. 1996;91:1795-1803.

92. Posserud I, Stotzer PO, Bjornsson ES, Abrahamsson H, Simren M. Small intestinal bacterial overgrowth in patients with irritable bowel syndrome. Gut. 2007;56:802-808.

93. Chan WW, Feldman N, Burakoff R. Risk factors for incomplete antibiotic treatment response in small intestinal bacterial overgrowth [abstract T1057]. Presented at Digestive Disease Week 2010; May 1-5, 2010; New Orleans, LA.

94. US Food and Drug Administration. Guidance for industry. Irritable bowel syndrome-clinical evaluation of products for treatment [draft]. US Department of Health and Human Services, US Food and Drug Administration, Center for Drug Evaluation and Research; 2010. Available from: http:// www.fda.gov/downloads/Drugs/GuidanceComplianceRegulatoryInformation/Guidances/UCM205269.pdf. Accessed February 3, 2012. 


\section{Supplementary Tables}




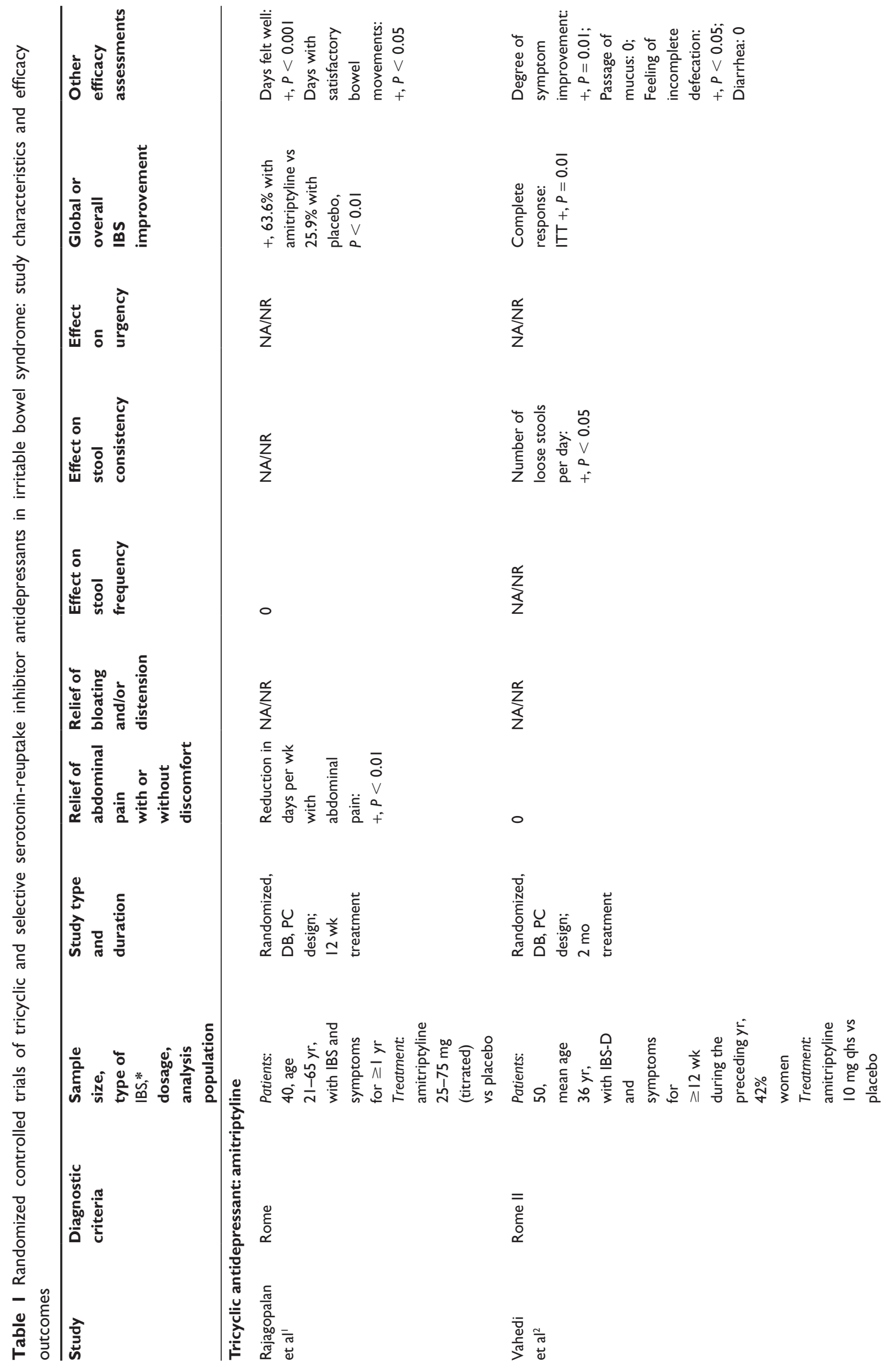




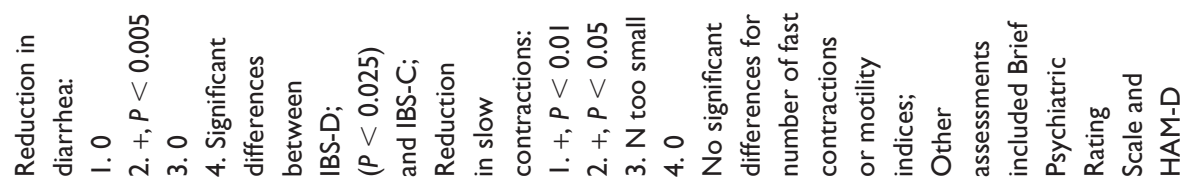

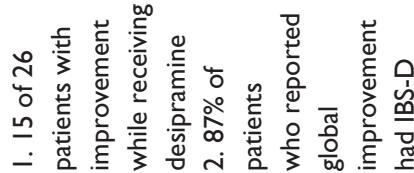

$\sum_{z}^{\infty}$

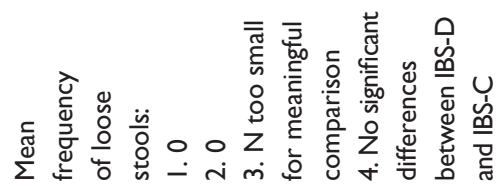

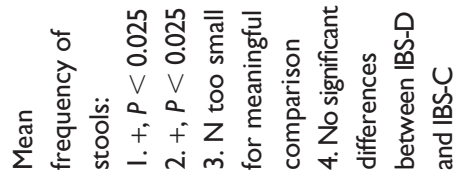

$\frac{o}{z}$

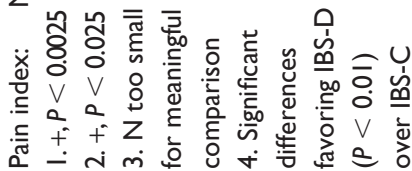

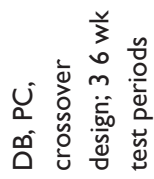

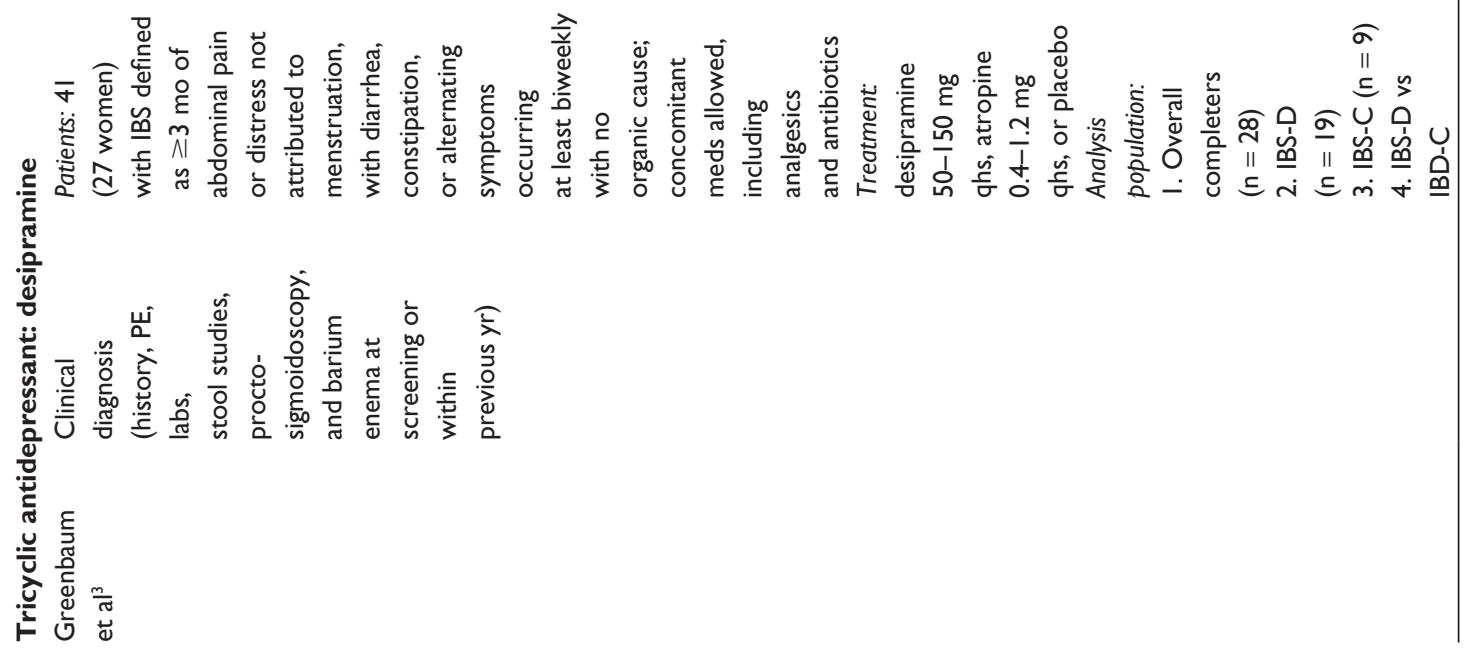




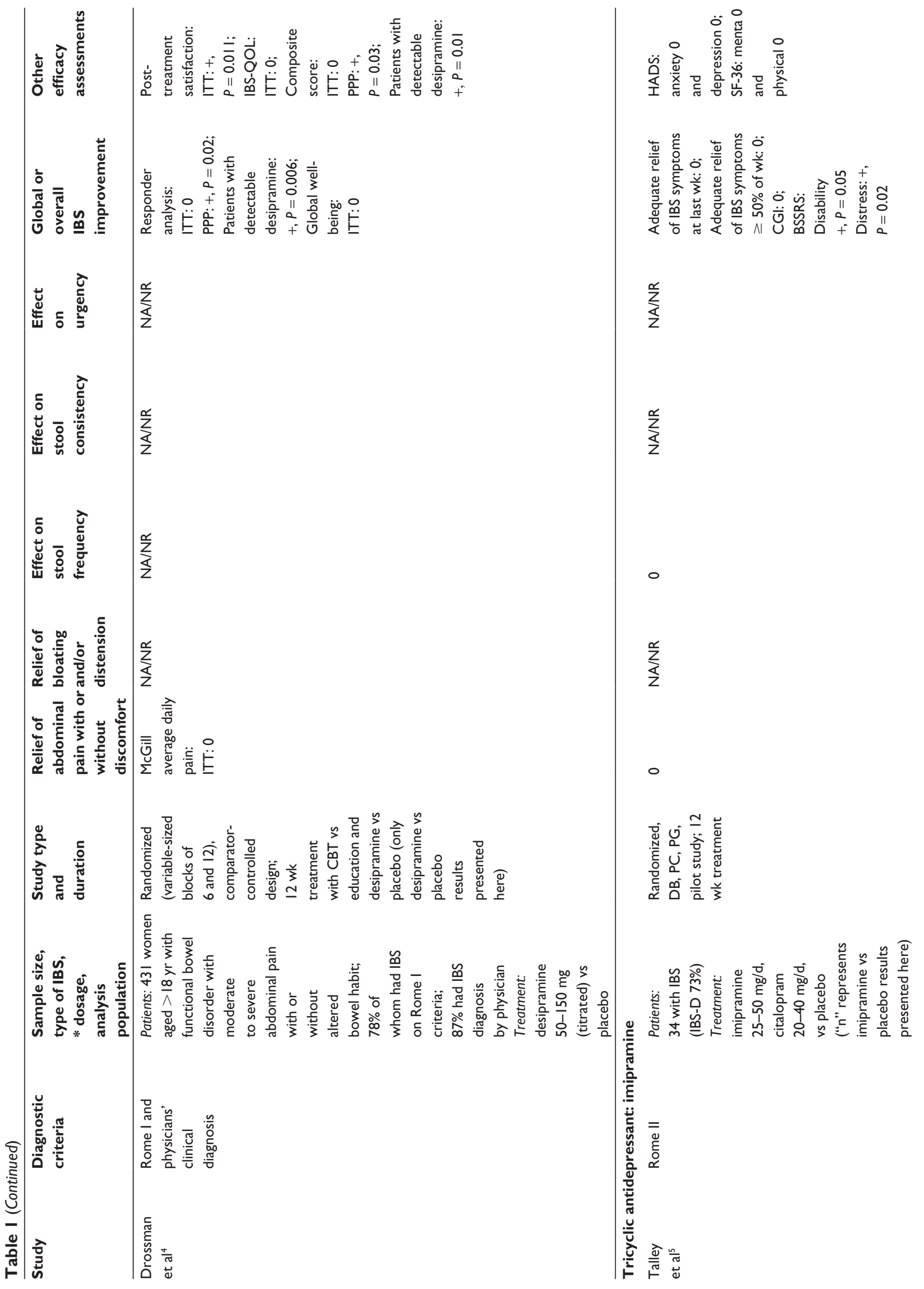




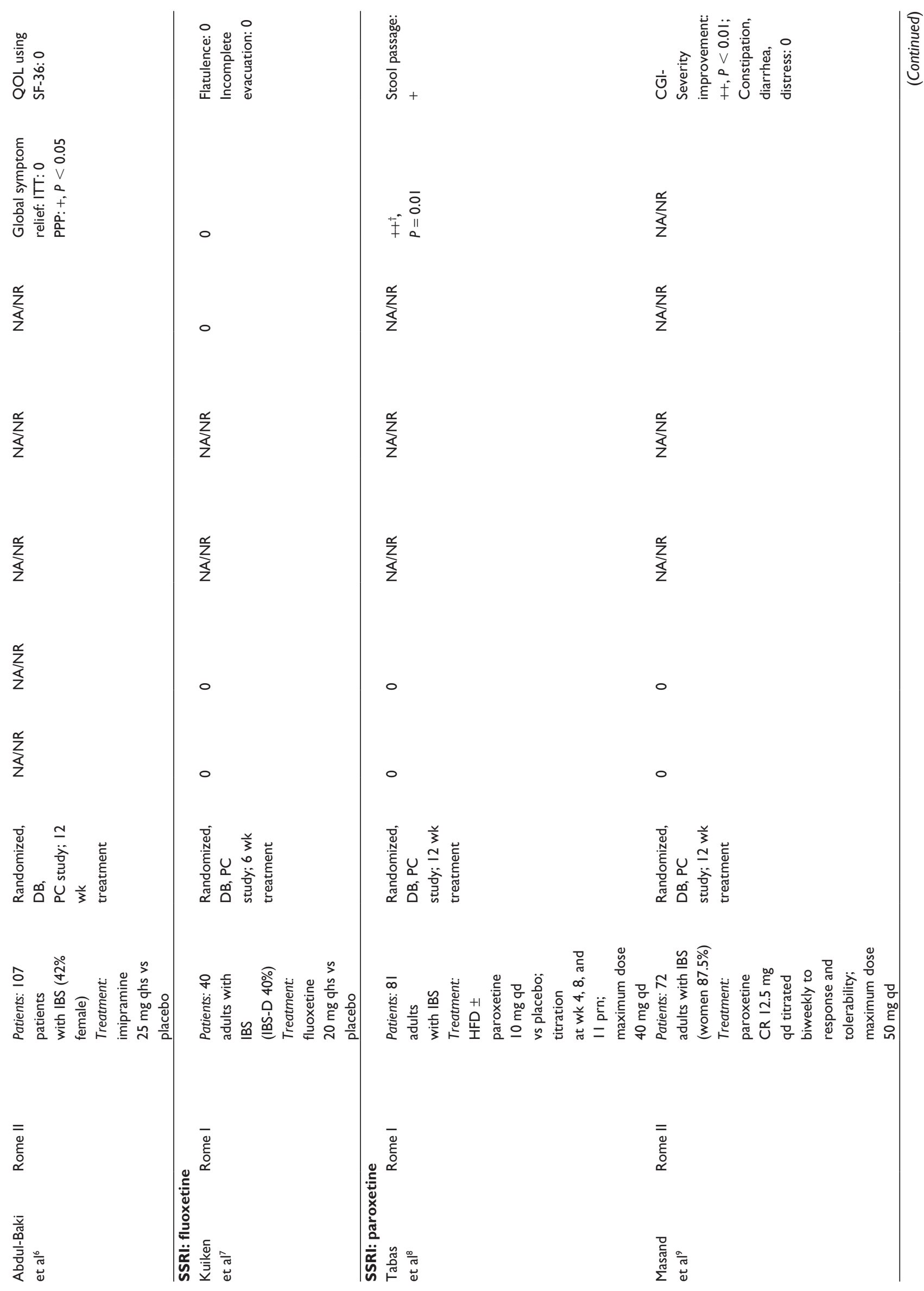




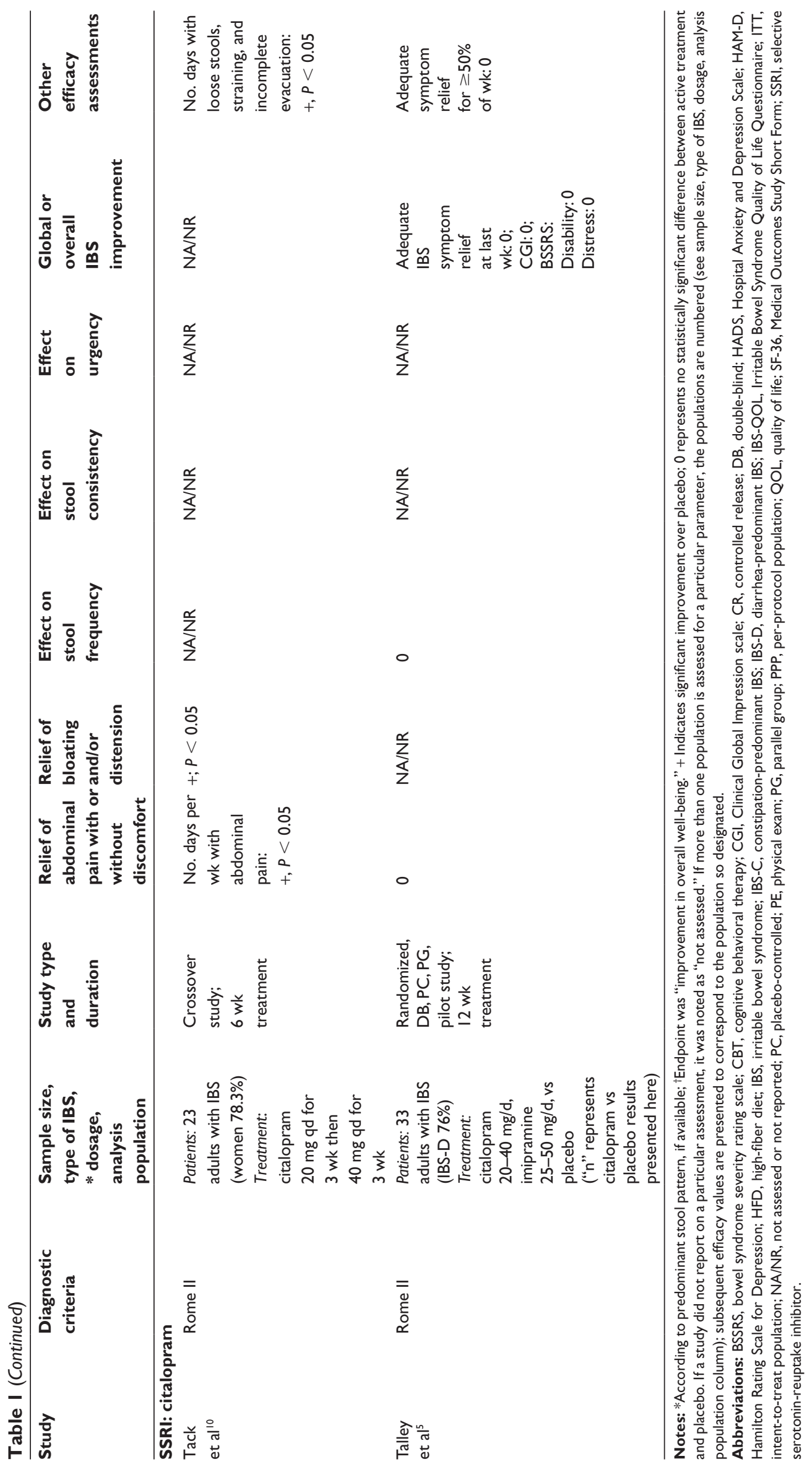




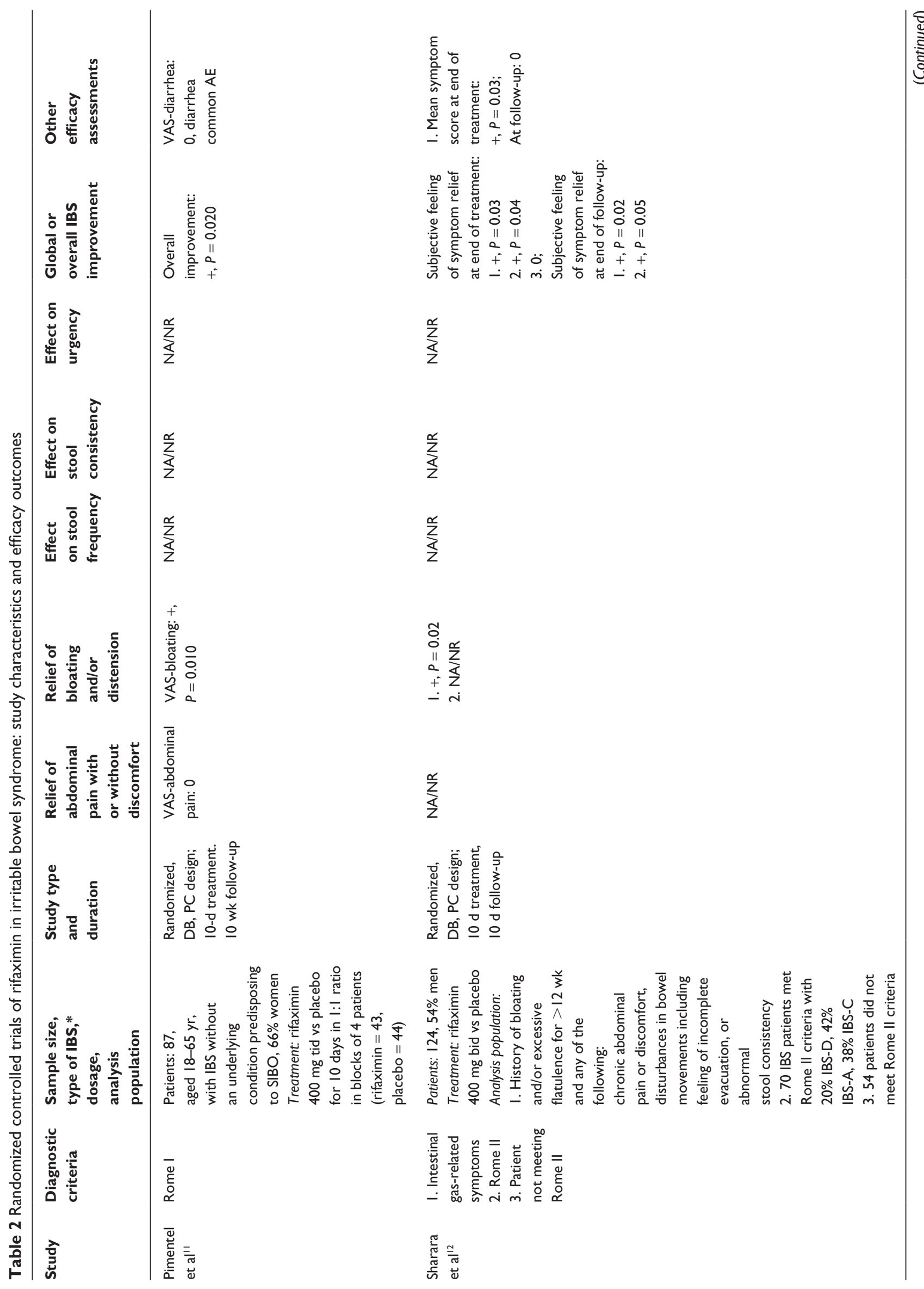




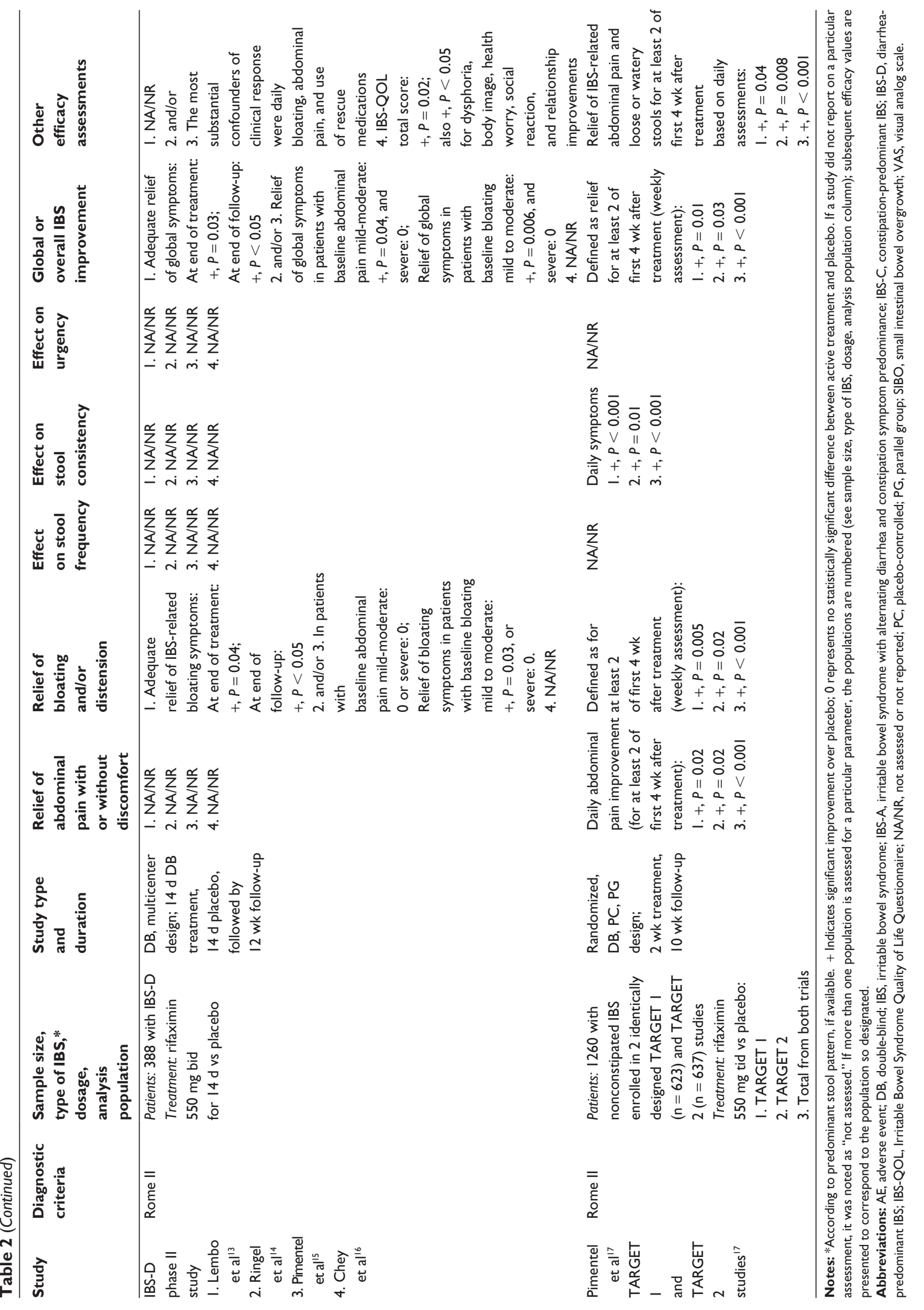




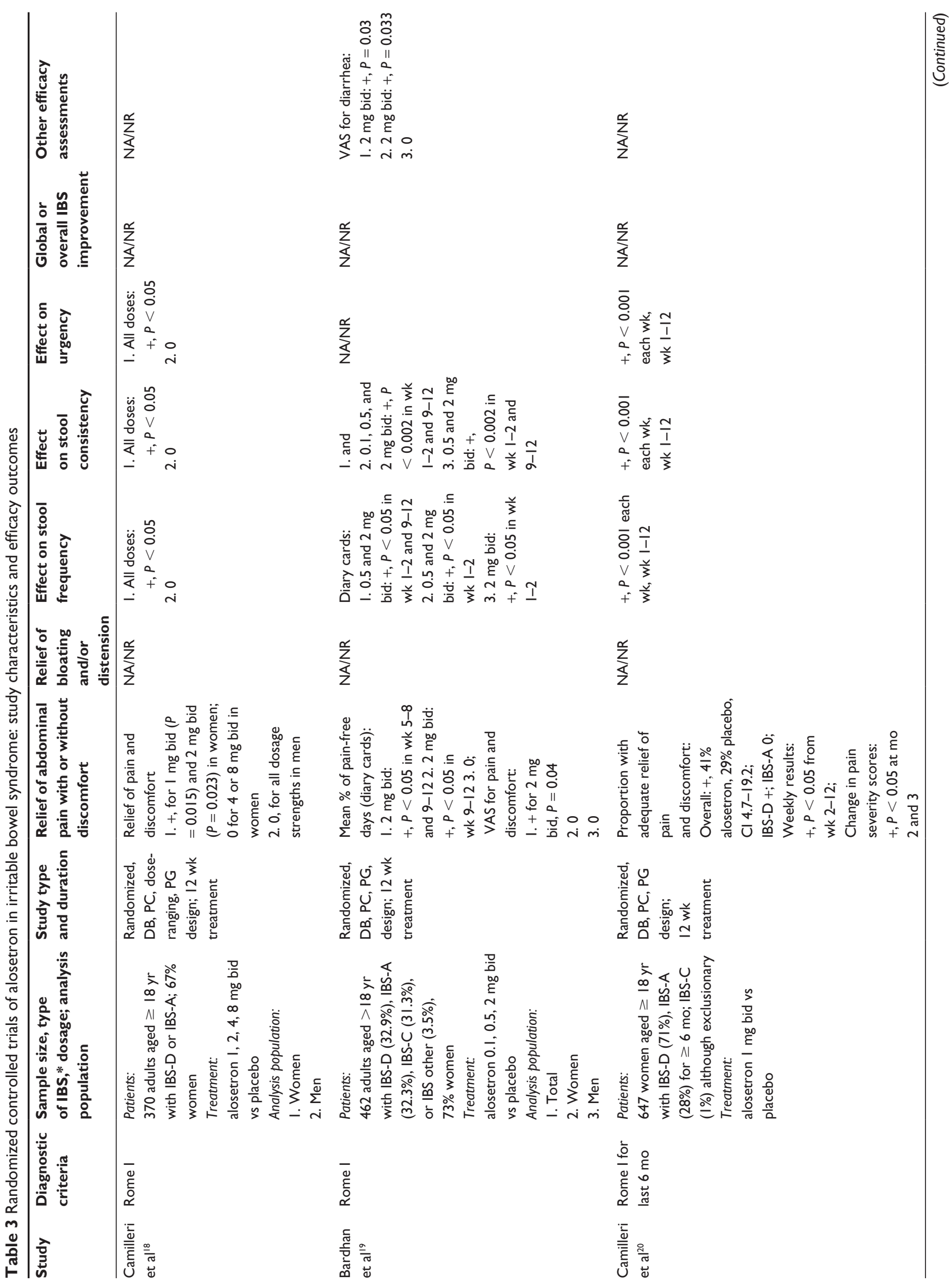




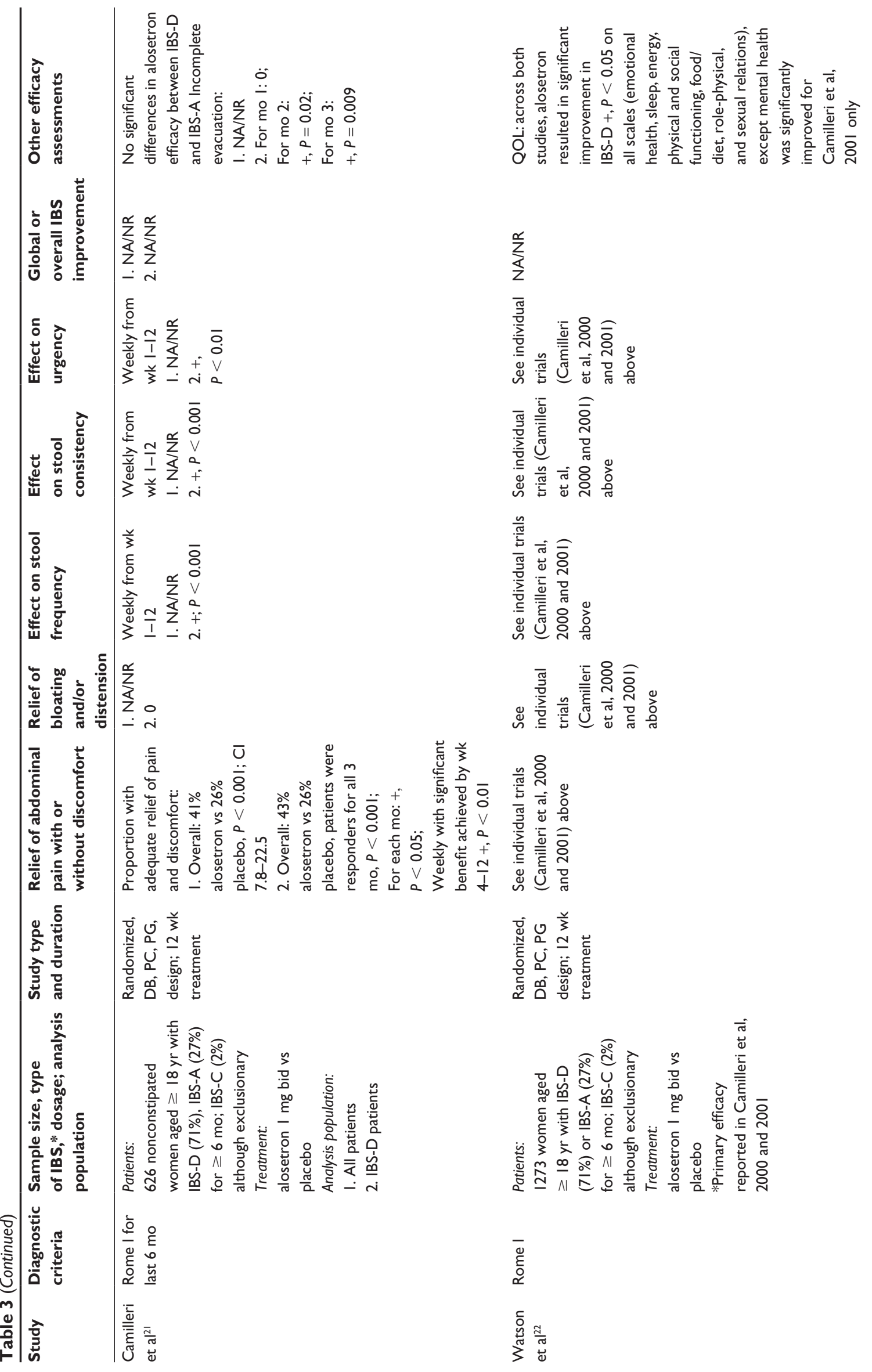




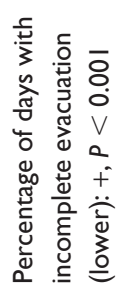

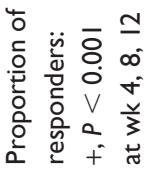

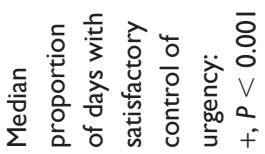

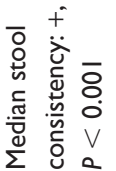

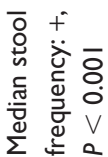

$\frac{o}{z}$

$\frac{\stackrel{r}{z}}{\sum}$

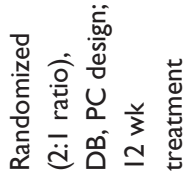

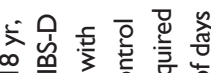

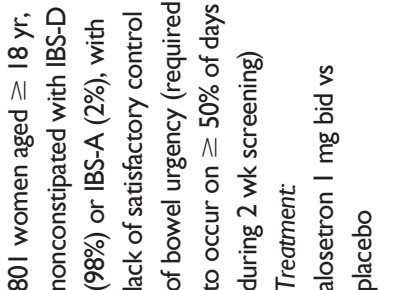

=

हैำ
ते
ò
ते
जू

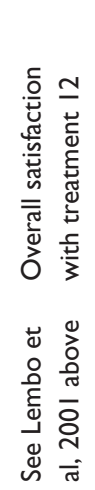

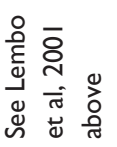

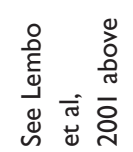

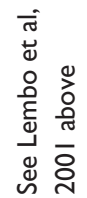

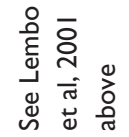

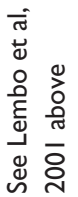

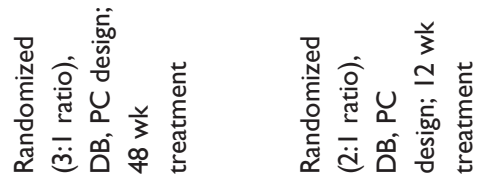

$\frac{\sim}{z}$

$\frac{o}{Z}$

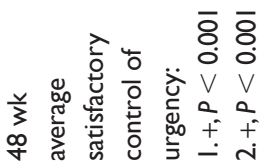

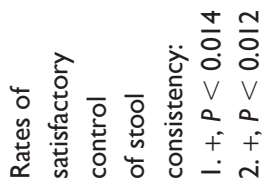

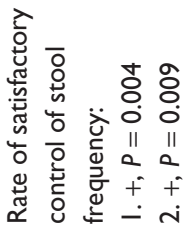

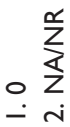

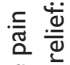

旁 节

岛 II 11

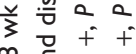

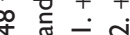

离远

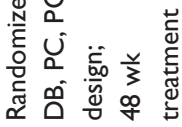

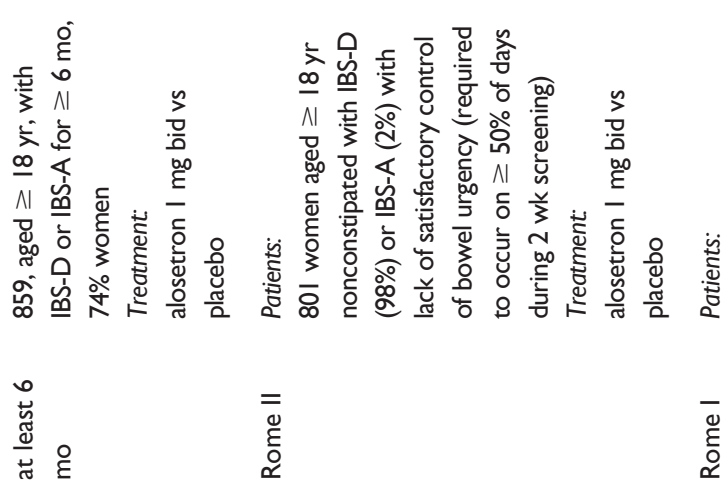

岂 $\frac{0}{\sqrt[0]{0}}$ 


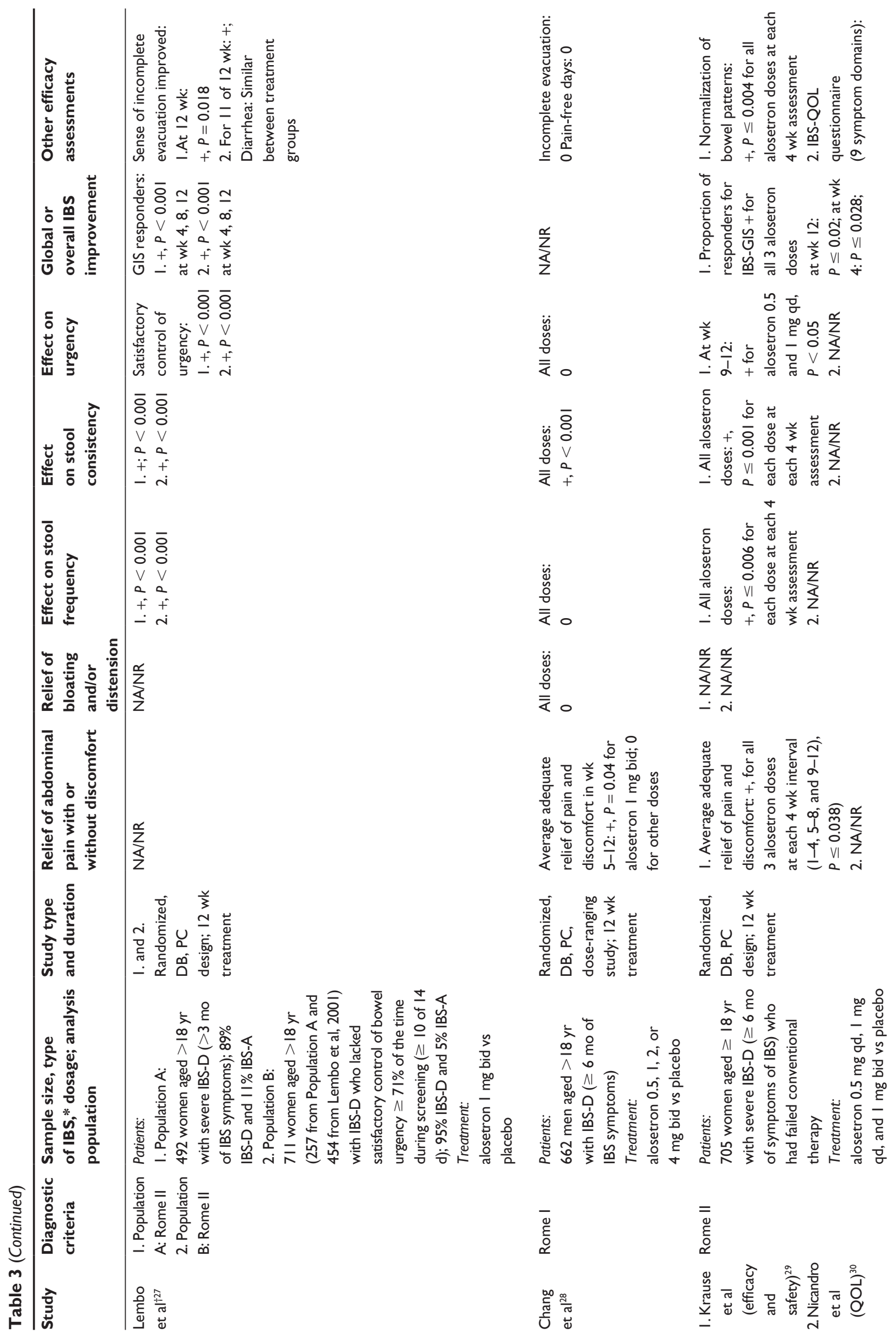



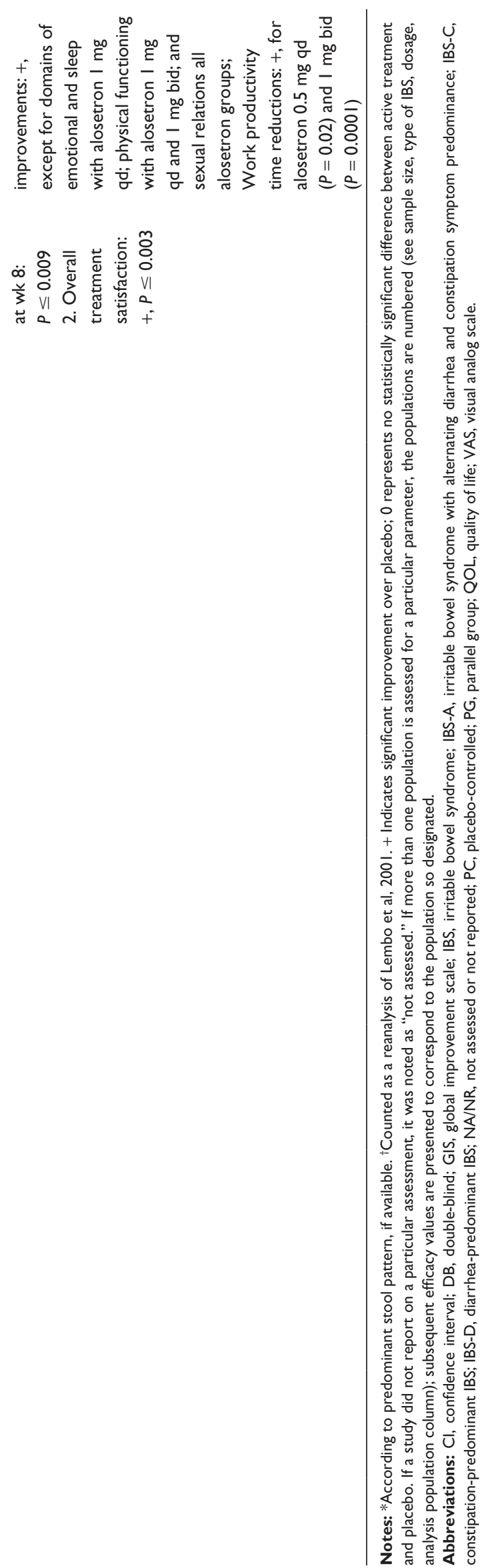


\section{References}

1. Rajagopalan M, Kurian G, John J. Symptom relief with amitriptyline in the irritable bowel syndrome. J Gastroenterol Hepatol. 1998;13:738-741.

2. Vahedi H, Merat S, Momtahen S, et al. Clinical trial: the effect of amitriptyline in patients with diarrhoea-predominant irritable bowel syndrome. Aliment Pharmacol Ther. 2008;27:678-684.

3. Greenbaum DS, Mayle JE, Vanegeren LE, et al. Effects of desipramine on irritable bowel syndrome compared with atropine and placebo. Dig Dis Sci. 1987;32:257-266.

4. Drossman DA, Toner BB, Whitehead WE, et al. Cognitive-behavioral therapy versus education and desipramine versus placebo for moderate to severe functional bowel disorders. Gastroenterology. 2003;125:19-31.

5. Talley NJ, Kellow JE, Boyce P, Tennant C, Huskic S, Jones M. Antidepressant therapy (imipramine and citalopram) for irritable bowel syndrome: a double-blind, randomized, placebo-controlled trial. Dig Dis Sci. 2008;53:108-115.

6. Abdul-Baki H, El Hajj II, Elzahabi L, et al. A randomized controlled trial of imipramine in patients with irritable bowel syndrome. World $J$ Gastroenterol. 2009;15:3636-3642.

7. Kuiken SD, Tytgat GN, Boeckxstaens GE. The selective serotonin reuptake inhibitor fluoxetine does not change rectal sensitivity and symptoms in patients with irritable bowel syndrome: a double blind, randomized, placebo-controlled study. Clin Gastroenterol Hepatol. 2003;1:219-228.

8. Tabas G, Beaves M, Wang J, Friday P, Mardini H, Arnold G. Paroxetine to treat irritable bowel syndrome not responding to high-fiber diet: a double-blind, placebo-controlled trial. Am J Gastroenterol. 2004;99:914-920.

9. Masand PS, Pae CU, Krulewicz S, et al. A double-blind, randomized, placebo-controlled trial of paroxetine controlled-release in irritable bowel syndrome. Psychosomatics. 2009;50:78-86.

10. Tack J, Broekaert D, Fischler B, Van Oudenhove L, Gevers AM, Janssens J. A controlled crossover study of the selective serotonin reuptake inhibitor citalopram in irritable bowel syndrome. Gut. 2006;55:1095-1103.

11. Pimentel M, Park S, Mirocha J, Kane SV, Kong Y. The effect of a nonabsorbed oral antibiotic (rifaximin) on the symptoms of the irritable bowel syndrome: a randomized trial. Ann Intern Med. 2006;145:557-563.

12. Sharara AI, Aoun E, Abdul-Baki H, Mounzer R, Sidani S, Elhajj I. A randomized double-blind placebo-controlled trial of rifaximin in patients with abdominal bloating and flatulence. Am J Gastroenterol. 2006;101:326-333.

13. Lembo A, Zakko SF, Ferreira NL, et al. Rifaximin for the treatment of diarrhea associated irritable bowel syndrome: short term treatment leading to long term sustained response [abstract T1390]. Gastroenterology. 2008;134 suppl. 1:A-545.

14. RingelY, Palsson OS, Zakko SF. Predictors of clinical response from a hase 2 multi-center efficacy trial using rifaximin, a gut-selective, non-absorbed antibiotic for the treatment of diarrhea associated irritable bowel syndrome [abstract T1411]. Gastroenterology. 2008;134 Suppl. 1:A550.

15. Pimentel M, Ringel Y, Brooks C, Bortey E, Forbes W. Severity of irritable bowel syndrome-related symptoms predicts clinical response to the nonsystemic antibiotic rifaximin [abstract P1065]. Presented at the 73rd annual meeting of the American College of Gastroenterology; October 3-8, 2008; Orlando, FL.

Clinical and Experimental Gastroenterology

\section{Publish your work in this journal}

Clinical and Experimental Gastroenterology is an international, peerreviewed, open access journal, publishing all aspects of gastroenterology in the clinic and laboratory, including: Pathology, pathophysiology of gastrointestinal disease; Investigation and treatment of gastointestinal disease; Pharmacology of drugs used in the alimentary tract;
16. Chey WD, Talley NJ, Lembo A, Yu A, Bortey E. Rifaximin significantly improves quality of life versus placebo in patients with diarrheapredominant irritable bowel syndrome [abstract P691]. Presented at the 73rd annual meeting of the American College of Gastroenterology; October 3-8, 2008; Orlando, FL.

17. Pimentel M, Lembo A, Chey WD, et al. Rifaximin therapy for patients with irritable bowel syndrome without constipation. $N$ Engl J Med. 2011;364:22-32.

18. Camilleri M, Mayer EA, Drossman DA, et al. Improvement in pain and bowel function in female irritable bowel patients with alosetron, a 5-HT3 receptor antagonist. Aliment Pharmacol Ther. 1999;13:1149-1159.

19. Bardhan KD, Bodemar G, Geldof H, et al. A double-blind, randomized, placebo-controlled dose-ranging study to evaluate the efficacy of alosetron in the treatment of irritable bowel syndrome. Aliment Pharmacol Ther. 2000;14:23-34.

20. Camilleri M, Northcutt AR, Kong S, Dukes GE, McSorley D, Mangel AW. Efficacy and safety of alosetron in women with irritable bowel syndrome: a randomised, placebo-controlled trial. Lancet. 2000;355:1035-1040.

21. Camilleri M, Chey WY, Mayer EA, et al. A randomized controlled clinical trial of the serotonin type 3 receptor antagonist alosetron in women with diarrhea-predominant irritable bowel syndrome. Arch Intern Med. 2001;161:1733-1740.

22. Watson ME, Lacey L, Kong S, et al. Alosetron improves quality of life in women with diarrhea-predominant irritable bowel syndrome. Am J Gastroenterol. 2001;96:455-459.

23. Lembo T, Wright RA, Bagby B, et al. Alosetron controls bowel urgency and provides global symptom improvement in women with diarrhea-predominant irritable bowel syndrome. Am J Gastroenterol. 2001;96:2662-2670.

24. Wolfe SG, Chey WY, Washington MK, et al. Tolerability and safety of alosetron during long-term administration in female and male irritable bowel syndrome patients. Am J Gastroenterol. 2001;96:803-811.

25. Olden K, DeGarmo RG, Jhingran P, et al. Patient satisfaction with alosetron for the treatment of women with diarrhea-predominant irritable bowel syndrome. Am J Gastroenterol. 2002;97:3139-3146.

26. Chey WD, Chey WY, Heath AT, et al. Long-term safety and efficacy of alosetron in women with severe diarrhea-predominant irritable bowel syndrome. Am J Gastroenterol. 2004;99:2195-2203.

27. Lembo AJ, Olden KW, Ameen VZ, Gordon SL, Heath AT, Carter EG. Effect of alosetron on bowel urgency and global symptoms in women with severe, diarrhea-predominant irritable bowel syndrome: analysis of two controlled trials. Clin Gastroenterol Hepatol. 2004;2:675-682.

28. Chang L, Ameen VZ, Dukes GE, McSorley DJ, Carter EG, Mayer EA. A dose-ranging, phase II study of the efficacy and safety of alosetron in men with diarrhea-predominant IBS. Am J Gastroenterol. 2005;100:115-123.

29. Krause R, Ameen V, Gordon SH, et al. A randomized, double-blind, placebo-controlled study to assess efficacy and safety of $0.5 \mathrm{mg}$ and $1 \mathrm{mg}$ alosetron in women with severe diarrhea-predominant IBS. Am J Gastroenterol. 2007;102:1709-1719.

30. Nicandro JPA, Shin P, Shringarpure R, Chuang E, Pan H. Alosetron is associated with improvements in treatment satisfaction and quality of life [abstract M1058]. Presented at the Digestive Disease Week 2010, May 1-5, 2010, New Orleans, LA.

Immunology/genetics/genomics related to gastrointestinal disease. This journal is indexed on CAS. The manuscript management system is completely online and includes a very quick and fair peer-review system. Visit http://www.dovepress.com/testimonials.php to read real quotes from published authors. 